\title{
Análisis del Cambio en un Problema de Adicción al Alcohol. Estudio de Caso
}

\section{An Analysis of Change in an Alcohol Addiction Problem. Case Study}

\author{
Gala Almazán Antón, Marina González Biber y Miriam Rocha Díaz \\ Instituto Terapéutico de Madrid (ITEMA), España
}

\begin{abstract}
Resumen. Se analiza el caso de C., una mujer que acude a consulta por problemas con el consumo de alcohol y un bajo estado de ánimo. El objetivo de este artículo es exponer un caso abordado con éxito desde la terapia de conducta justificando los progresos obtenidos a través de la operativización de las medidas de cambio. Los resultados obtenidos muestran una tendencia general positiva en las medidas de cambio establecidas (consumo de alcohol, interacciones sociales, estado de ánimo, nivel de actividad, dificultades para dormir, etc.), a pesar de las dificultades que presentaba el caso por ser varias las áreas problemáticas asociadas y por la reticencia al cambio de la cliente. Estos dos factores están muy presentes en este tipo de problemática y los clínicos deben permanecer en alerta ante posibles caídas o recaídas, tan frecuentes en los casos de abuso o dependencia al alcohol.

Palabras clave: dependencia, alcohol, modificación de conducta, cambio, alcoholismo, estudio de caso.
\end{abstract}

\begin{abstract}
This paper analyses the case of C., a woman treated for alcohol addiction and other associated problems. The aim is to present a case which has been successfully addressed from a cognitive and behavioral therapy approach, and where all progress achieved can be justified through the operationalization of change measures. The results obtained show an overall positive trend in almost all registered change measures, despite the difficulties presented due to several problem areas associated with the case, and client's reluctance to change. These two factors are often present in this type of problem, and clinicians would do well to remain alert to possible relapses, which are so common in cases of alcohol abuse or dependence.

Keywords: dependence, alcohol, behavior modification, change, alcoholism, case study.
\end{abstract}

\section{Exposición del caso}

\section{Descripción inicial}

El análisis funcional del problema mostró un consumo excesivo de alcohol discriminado por el tipo de actividades que realizaba la cliente $\mathrm{u}$ horas del día en las que se encontraba, lugares o personas asociados a la conducta de consumo, cambios en su estado de ánimo (mediados por pensamientos negativos relacionados consigo misma y con su situación actual y

La correspondencia sobre este artículo dirigirla a la primera autora al e-mail: gala.almazan@gmail.com futura) y síntomas físicos de la abstinencia. Pero esta conducta era controlada por la presencia de su hija, quien ejercía la función de castigo del consumo y del hecho de mostrarse ebria ante ella. Si bien este problema se veía mantenido (por mecanismos de reforzamiento positivo y negativo) a corto plazo por las consecuencias obtenidas (alivio del malestar, sensaciones agradables, etc.), a largo plazo le generaba emociones negativas. Esto unido a su situación de inactividad (ausencia de reforzadores), la condujo a un estado de ánimo muy bajo, caracterizado por pensamientos negativos sobre su momento actual de vida, sobre su propia persona y sobre su futuro, así 
como por el ya mencionado bajo nivel de actividad y baja exposición a experiencias de refuerzo.

Para la elaboración de este artículo se han tenido en cuenta las cuatro sesiones iniciales de evaluación, una quinta de devolución del análisis funcional y quince sesiones de tratamiento (5 destinadas a trabajar la dependencia física -que correspondieron a la fase de desintoxicación- y 9 sesiones en las que se trabajó la dependencia psicológica -fase de deshabituación-). Todas ellas se llevaron a cabo con una periodicidad semanal y fueron de una hora de duración. También se han llevado a cabo tres sesiones de seguimiento mensual que no han sido tenidas en cuenta para el artículo, pues el caso todavía no ha finalizado.

\section{Sujeto}

A continuación presentamos el caso de C., una mujer de 58 años de edad que decidió ponerse en tratamiento psicológico por un problema de adicción a la bebida y un bajo estado anímico. C. acudió a tratamiento instada por su única hija (de 23 años de edad), tras haberle estado negando su problema con el alcohol durante 4 meses. C. se quedó viuda hace tres años, tras perder a su marido por un tumor cerebral, con quien llevaba 20 años casada y mantenía una estrecha relación. Durante el proceso de enfermedad de su marido, a ella le detectaron un cáncer de mama. Empezó en ese momento a recibir quimio y radioterapia, y finalmente le extirparon el pecho. Coincidiendo con este duro proceso, comenzaron a gestarse sus problemas con la bebida. Debido a su consumo de tabaco, la cliente también presentaba problemas respiratorios, que se veían agravados por el sobrepeso (104 kg) y el consumo de alcohol (dado su efecto depresor sobre la función respiratoria). Por todo ello recibió la baja laboral que posteriormente se convirtió en una incapacidad permanente del $50 \%$ por una lesión posterior en el hombro como consecuencia de una caída, lo que implicó que no volviera a trabajar. Este nuevo estatus le repercutió anímica y económicamente, pues se vieron reducidos su nivel de actividad y sus ingresos, teniendo que hacer frente a deudas. Por otro lado aún seguía recordando a su marido con mucha frecuencia y si bien esto le generaba emociones positivas a corto plazo, a largo plazo suponía un mantenimiento del malestar debido a la ausencia del mismo y a la tendencia a comparar su situación actual con las circunstancias pasadas que ella percibía como mejores. En cuanto al consumo de alcohol, pese a que le reportaba tranquilidad y bienestar, reconocía también sus efectos negativos. Al llegar a consulta dijo estar dispuesta a intentarlo y a comprometerse con la terapia.

Desde la muerte de su marido, $\mathrm{C}$. tomaba medicación antidepresiva (Orfidal ${ }^{\circledR} 1 \mathrm{mg}$ 1-0-1 desde hacía dos años y Xeristar ${ }^{\circledR} 60$ mg 1-0-0 desde hacía tres años), a la que se suma la medicación prescrita para sus problemas respiratorios (Terbasmin ${ }^{\circledR}$ y Spiriva ®). Durante la intervención C. empezó a experimentar intensos dolores musculares que a veces la invalidaban bastante y que los médicos relacionaron con una posible fibromialgia (cuyo diagnóstico aún no se ha confirmado). En lo que a la ingesta de alcohol se refiere, antes de casarse la cliente no consumía alcohol pero a partir de entonces comenzó un consumo social y muy esporádico (una o dos copas al mes). Sin embargo, cuando empezaron los problemas de salud suyos y de su marido, comenzó a beber una copa al volver de la quimioterapia, porque esto la relajaba mucho y también le daba fuerzas para afrontar el ver a su marido postrado en la cama. De forma que el comienzo de la dependencia se sitúa hace 5 años con el inicio de la enfermedad de ambos. Poco a poco empezó a abusar más y cuando murió su marido llegó a tomar alcohol a cualquier hora del día. El nivel de consumo en el momento de llegar a consulta era de una media de 2 copas al día de whiskey con coca-cola, que se podía incrementar hasta 4-5 copas al día. Reconocía que 1-2 veces al mes se pasaba con las copas y al día siguiente padecía el síndrome de abstinencia, recurriendo entonces a beber más para aplacarlo. Las rutinas de C., en el momento de acudir a nosotros, eran consideradas por ella como "poco gratificantes y monótonas", manifestando así ganas de cambiar su estilo de vida. Aunque siempre fue una mujer con inquietudes y ocupaciones, ahora se encontraba sin interés ni ganas de hacer nada. Dejó de salir con familiares y amigos porque eran contextos muy asociados a su marido que, por tanto, le recordaban a él.

Al llegar a nuestra clínica, expuso que le gustaría 
que le ayudásemos tanto con el consumo de alcohol como a "organizar" su vida. Las razones que esgrimía para dejar la bebida eran: deseo de aprender otras estrategias para afrontar situaciones difíciles, ahorrar dinero, eliminar un factor de riesgo en su salud, evitar consecuencias negativas derivadas del consumo para su desempeño diario (pérdidas de memoria y de agilidad, habituación y tolerancia, dificultades al hablar, etc.) y evitar preocupar a su hija. Por lo que, a partir de estas demandas, se establecieron los siguientes objetivos clínicos:

1. Eliminación del consumo de alcohol.

2. Mejora del estado de ánimo.

\section{Evaluación y Análisis Funcional}

Por su metodología, este artículo se basa en el análisis de caso único. De esta manera, hemos podido llevar a cabo un estudio de la situación natural de la cliente, contemplando todas las variables que pueden estar manteniendo el problema, sin riesgo de perder información, en contraste con los estudios experimentales más artificiales, tal como apunta Valero (2009).

Como estrategias de evaluación se emplearon la entrevista clínica no estructurada y autorregistros (del consumo de alcohol y de las actividades diarias). Asimismo, para hacer un seguimiento objetivo y fiable del caso se grabaron las sesiones bajo consentimiento previo del centro y la cliente (informándole que a ella en ningún momento se la iba a grabar en imagen -sólo en audio- ya que sólo se veía a la terapeuta), y fueron posteriormente revisadas por parte de las tres autoras, discutiendo las diferentes medidas de cambio que se iban identificando. Las sesiones se grabaron con el fin de analizar, entre otras variables, las verbalizaciones emitidas en sesión por la cliente, ya que éstas han sido una parte fundamental del análisis. Basándonos en Froján, Montaño, Calero y Ruiz (2011), la importancia del análisis de las verbalizaciones se puede justificar por el hecho de que el cliente habla de sus problemas y describe lo que ocurre fuera de la clínica y en base a estas descripciones se planifica y pone en marcha el programa terapéutico. Dado que una de las autoras fue la terapeuta del caso, con el fin de que este fac- tor no sesgara la información obtenida por medio de las grabaciones, se buscó la máxima coincidencia en todos los criterios. Asimismo, fue la terapeuta quien pudo informar de aspectos que no se podían registrar con las grabaciones que hacían alusión, especialmente, a la comunicación no verbal (gestos, expresión de emociones, etc.).

Por otra parte, durante la evaluación se recurrió a su hija y a la hermana de C. para corroborar la información aportada por ésta en las entrevistas, siempre con su consentimiento (esta colaboración también se mantuvo durante la intervención y el seguimiento). En este sentido, C. se opuso inicialmente a que contactásemos con alguien de su contexto y además algunas personas no disponían de tiempo ni querían implicarse demasiado. No obstante, el método general de evaluación se basó en la entrevista y en diferentes registros que se le iban encargando a la cliente (de actividades, de consumo de alcohol, etc.). Con respecto a la periodicidad de las sesiones, inicialmente fue semanal y después se fue ajustando en función de las necesidades de la intervención. Durante la fase de desintoxicación se decidió hacer un seguimiento telefónico y por correo electrónico; concretamente, C. debía enviar los registros por correo cada 1-2 días para asegurarnos de que no lo dejaba para el final y darle feedback lo más inmediatamente posible. También se mantuvieron contactos telefónicos puntuales con su hija y su hermana con este propósito.

En todo momento se destacó la importancia de la sinceridad y C. se mostró de acuerdo en este aspecto, asegurando que no quería mentir a su hija y que sabía que si mentía se perjudicaba a sí misma.

Hay que tener en cuenta que el caso sigue en fase de seguimiento, pues este tipo de problemas requieren un control muy continuado y prolongado en el tiempo. Actualmente viene a consulta cada mes y medio o dos meses.

A continuación, se presenta el análisis funcional elaborado en base al modelo propuesto por Segura, Sánchez y Barbado (1991).

\section{Variables Disposicionales}

a) Del entorno: Aquí cabe resaltar, como antecedentes lejanos, la enfermedad (hace 5 años) y 
posterior fallecimiento de su marido (hace 3 años) a causa de un tumor cerebral. Por otro lado, la situación económica de la cliente era bastante difícil. C. también disponía de un círculo de amistades desde hace varios años (otras parejas), todas ellas compartidas con su marido.

b) Del individuo: C. empezó a trabajar con 12 años y no pudo acabar el colegio (fue con 45 años cuando se sacó el Graduado Escolar, su máximo nivel académico, por lo que su nivel cultural es medio-bajo). La mayor parte del tiempo estuvo trabajando para la industria cinematográfica. Sus padres fallecieron de cáncer (teniendo que cuidar ella de sus hermanos). Después conoció a su marido, quien enfermó al mismo tiempo que ella padecía un cáncer de mama (tratado y remitido). Recordaba esta etapa como "muy agobiante", ya que además de ir sola al hospital, tenía que cuidar de su marido. Tras el fallecimiento de éste, C. quedó muy afectada y estuvo tomando Xeristar ${ }^{\circledR}$ (con duloxetina como principio activo) $60 \mathrm{mg}$ (1-0-0) y Orfidal ${ }^{\circledR}$ (con lorazepam con principio activo) $1 \mathrm{mg}$ (1-0-1). En este sentido, advertimos que esta medicación podía producir efectos secundarios como insomnio, pesadillas, reducción de la capacidad intelectual, ansiedad, temblores, dolor músculo-esquelético, etc. Estos efectos se suman a los posibles efectos secundarios de la medicación para sus problemas respiratorios: Terbasmin @ 500 microgramos (2-0-2) y Spiriva ${ }^{\circledR} 18$ microgramos (1-0-0), los cuales pueden producir temblores, aceleración del ritmo cardiaco, y más raramente, dificultad para dormir, cambios de humor, mareos, dolores de cabeza, tos, pitos o falta de respiración, ronquera e hinchazón. Todos ellos se tuvieron en cuenta de cara a la evaluación, pues podían estar agravando la situación de la cliente (ej.: más despistes -no sólo debidos al alcohol-, alteraciones en el estado emocional, etc.), aunque no alteraron la planificación de la intervención, centrándose ésta igualmente en resolver el problema actual de la cliente (con independencia del grado de contribución de la medicación a dicho estado).
En lo que al consumo de alcohol se refiere, si bien anteriormente sólo bebía de forma puntual con amigos, pasó a tomar una media de dos copas al día de whiskey (40\%) con Coca-Cola (60\%). Otras veces se pasaba y podía llegar a tomar hasta 5 copas diarias. Esos días iban seguidos de molestias físicas (dolor de cabeza, temblores y malestar general) que se le pasaban si tomaba otra copa, aunque a veces conseguía resistirse a la tentación. Generalmente, las tomaba siempre en los mismos dos bares del barrio y a la misma hora (al volver del paseo). Pese a todo, inicialmente no reconoció su problema con el alcohol, aunque su hija empezó a sospechar. Por otro lado, siempre le había gustado salir, estar rodeada de gente, leer, aprender cosas nuevas, etc. pero perdió la ilusión en la medida en que todo le recordaba a su marido (por lo que sus allegados se condicionaron negativamente, convirtiéndose en estímulos elicitadores de malestar). La única pareja que veía con mayor frecuencia la constituían dos amigos del barrio con los que empezó a tener la costumbre de ir al bar a beber. Su actividad laboral también había sido siempre muy intensa, ocupando gran parte de su tiempo. Sin embargo, debido a su baja laboral, a su incapacidad y a su inactividad, cuando C. llegó a consulta hacía mucho tiempo que no salía. En cualquier caso, decía tener la habilidad de "apartar pensamientos negativos" y "aparentar u obligarse a estar bien" (mostrando despreocupación, riéndose, etc.), compensando los malos momentos con los buenos. C. decía que tuvo que aprender a hacer esto con el paso del tiempo, dadas las experiencias por las que ha tenido que pasar en su vida.

\section{Variables Funcionales}

a) Hipótesis de Adquisición: A raíz de la gran cantidad de cambios que sufrió en su entorno, C. encontró en el alcohol la estrategia que le permitía adaptarse a su nueva situación hasta el punto de comenzar a abusar de la bebida y de caer en una situación de dependencia, al no disponer de otras estrategias de afrontamiento más adecuadas o eficaces. Concretamente, cuando su marido enfermó y ella tenía que acudir al hospital para recibir tratamiento, antes de 
subir a casa solía tomar una copa para "afrontar lo que se le venía encima”. Posteriormente, cuando falleció su marido, dejó de trabajar y su hija estaba muy implicada en las actividades académicas; este patrón de comportamiento también pudo verse reforzado o mantenido en la medida en que a $\mathrm{C}$. el alcohol también le daba "fuerzas" para afrontar la situación de verse sola en casa sin su marido y sin cosas que hacer ni con las que ocuparse (experimentando un cambio radical al pasar de estar muy ocupada a estar totalmente ociosa). Por lo que, con el tiempo (y tras experiencias repetidas en ese sentido), el hecho de ir al médico o al hospital y de volver a casa, ya generaba esas ganas de beber. En todo esto influyó el hecho de que C. tuviera pocas experiencias carentes de obligaciones, de modo que no tuvo ocasión de aprender a emplear su tiempo libre de forma satisfactoria. Debido a ello, y con la muerte de su marido reciente, $\mathrm{C}$. empezó a darle vueltas a las cosas (a su condición física y psicológica, a recuerdos obsesivos de los momentos felices de su vida anterior, verbalizaciones negativas sobre sí misma y su situación, etc.) que mermaron su estado anímico y dificultaron aun más su capacidad de adaptación. Intentó mantenerse ocupada (apuntándose a algunos cursos), pero estaba más pendiente de si disfrutaba o no (machacándose por no hacerlo como antes) que sólo percibía lo negativo de las situaciones, todo lo cual la desmotivó de cara a continuar haciendo actividades. Dado que además se lesionó el hombro, por miedo a volverse a caer, dejó de salir del barrio, lo cual también limitó el tipo o variedad de actividades a las que tenía acceso. De este modo, los momentos en los que C. bebía, si bien a corto plazo sentía fuerzas y un alivio del malestar (por lo que la conducta de ingesta se veía positiva y negativamente reforzada), a largo plazo le generaba pérdidas de memoria, problemas de salud, inestabilidad, desorganización, problemas con el habla, así como dependencia física y psicológica.

b) Hipótesis de Mantenimiento: En el momento de llegar a consulta, C. presentaba verbalizaciones negativas recurrentes relacionadas consigo misma, con su situación y con su futuro, así como un bajo nivel de actividad que implicó una pérdida importante de reforzadores. Concretamente, ante gran variedad y cantidad de situaciones diversas (ej.: al hacer algún curso, encontrarse a alguien, salir a pedir un adelanto al banco, al mirarse en un escaparate, etc.), C. generaba pensamientos y emociones negativas que discriminaban conductas evitativas (ej.: abandono de actividades, evitación de contactos sociales, etc.) y de consumo. En el caso de las actividades, concretamente, no eran ellas mismas las que provocaban tantos sentimientos de malestar (que a largo plazo podía ser así), sino más bien lo que $\mathrm{C}$. se decía a sí misma en tales situaciones. Este patrón de comportamiento se veía reforzado (y, por ende, mantenido hasta la actualidad) precisamente por las consecuencias que obtenía: en el primer caso, alivio del malestar y del esfuerzo que suponían tales actividades (pues si bien volver a quedar con amigos y rehacer su red social le podía suponer un aliciente a largo plazo, en ese momento le recordaban lo que había perdido y le suponía una ruptura con el patrón de inactividad al que se había habituado) y, en el segundo caso, disminución del malestar o aumento de las "fuerzas" para afrontar determinadas situaciones, así como disfrute con el sabor de la bebida. La conjunción de estos factores (mecanismos de reforzamiento positivo y negativo) propició de forma progresiva la pérdida de control y el establecimiento de la dependencia física y psicológica, hasta llegar a la situación en la que C. consumía, ya no para conseguir las consecuencias anteriormente mencionadas, sino para evitar también el malestar que experimentaba debido al síndrome de abstinencia. Y si bien C. experimentaba emociones negativas después de beber (mediadas por pensamientos negativos de culpabilidad), así como tenía que asumir el coste económico de la bebida, el riesgo de decepcionar a su hija y de experimentar otros problemas (de salud, de desorganización, de 
memoria, etc.), como todas estas consecuencias aparecían de forma demorada, no llegaban a adquirir la funcionalidad de castigo de la conducta de consumo, sino que simplemente constituían un elemento elicitador de más emociones negativas. Y tal y como ocurre en otros problemas adictivos, puesto que solía beber en los mismos sitios y con la misma gente, se acabó produciendo un proceso de generalización, de manera que $\mathrm{C}$. acabó condicionando los locales y las personas con las que solía consumir alcohol, lo cual implicó que su simple presencia elicitara esas ganas ("ansias") de beber. De hecho, era su hija la única que discriminaba la conducta de abstemia (precisamente para evitar preocuparla, discutir con ella, decepcionarla, etc. y sentirse mal por ello) y, en caso de producirse consumo, también discriminaba la conducta de mentirle sobre el mismo por los mismos motivos. Era ella quien también discriminaba otras conductas adaptativas, pues cuando estaba presente C. procuraba disimular su estado anímico para evitarle el sufrimiento. No obstante, no se puede descartar que también existiesen ganancias secundarias por el mantenimiento del problema de consumo, pues dado que su hija era la principal fuente de refuerzo y de apoyo para C., es posible que el problema constituyese una forma de mantenerla cerca y atenta.

\section{Intervención}

\section{Modelos de tratamiento de la adicción al alcohol}

Cuando los psicólogos nos enfrentamos a un problema de alcohol podemos optar por dos modelos de intervención: uno médico y otro psicológico (muchas veces complementarios). Los tratamientos médicos incluyen programas de desintoxicación que suponen la estancia del paciente en centros u hospitales especializados donde se utilizan fármacos para evitar el síndrome de abstinencia (de 2-3 semanas de duración), caracterizado por síntomas físicos (ej.: dolores de cabeza, insomnio, inapetencia, náuseas, temblor de manos, etc.) y psicológicos (ej.: nerviosismo, agitación, dificultad para pensar con claridad, fatiga, pesadillas, etc.). Tras este periodo de desintoxicación, puede someterse al paciente a diversos métodos de terapia psicológica (generalmente en forma grupal) para tratar los problemas psicológicos asociados o que hayan podido llevar al paciente a la dependencia. De hecho, en numerosos estudios se ha encontrado que cuando una persona es adicta a una sustancia, lo más habitual (hasta en un $50 \%-75 \%$ de los casos) es que presente otros problemas adicionales (Casas, 1994). Según Petrakis, González, Rosenkeck y Krystal (2002), los trastornos que más suelen aparecer ligados a la presencia de un problema de abuso de alcohol son la ansiedad y el bajo estado anímico, y la correlación de comorbilidad es mayor en los casos en los que existe una dependencia que en los que sólo presentan un abuso de alcohol. Los estudios que intentan asociar los problemas de abuso del alcohol con trastornos de personalidad no son concluyentes e incluso ponen en duda la operatividad de la propia clasificación de estos trastornos, dado que en muchos casos las personas que abusan del alcohol presentarían dos trastornos de personalidad (Fernández-Montalvo y Landa, 2003).

Uno de los grupos de "autoayuda" más conocidos es el de Alcohólicos Anónimos, una comunidad cuyos miembros se apoyan mutuamente para mantener la sobriedad, compartiendo la experiencia de recuperación con otras personas que puedan tener problemas similares con la bebida y deseen solucionarlos. No obstante, este modelo ha despertado algunas críticas, como el hecho de no distinguir entre la presencia o no de una dependencia química (y un síndrome de abstinencia) o su planteamiento de "un trago, un borracho", razón por la cual sólo se plantean como objetivo la abstemia y no un consumo controlado (Nathan, 1982). Por otra parte, algunos autores (Nathan, 1982) destacan el bajo nivel de éxito de esta organización (entre el 30\% y el 35\%).

Dentro del enfoque psicológico, sin embargo, sí se hace tal distinción, pues mientras que en los casos de dependencia sí se recurre a programas de desintoxicación para lograr la abstinencia, en los casos en los que hay un simple abuso o mal uso del alcohol (pero no dependencia) no. En este sentido, conviene 
Cuadro 1. Secuencias funcionales

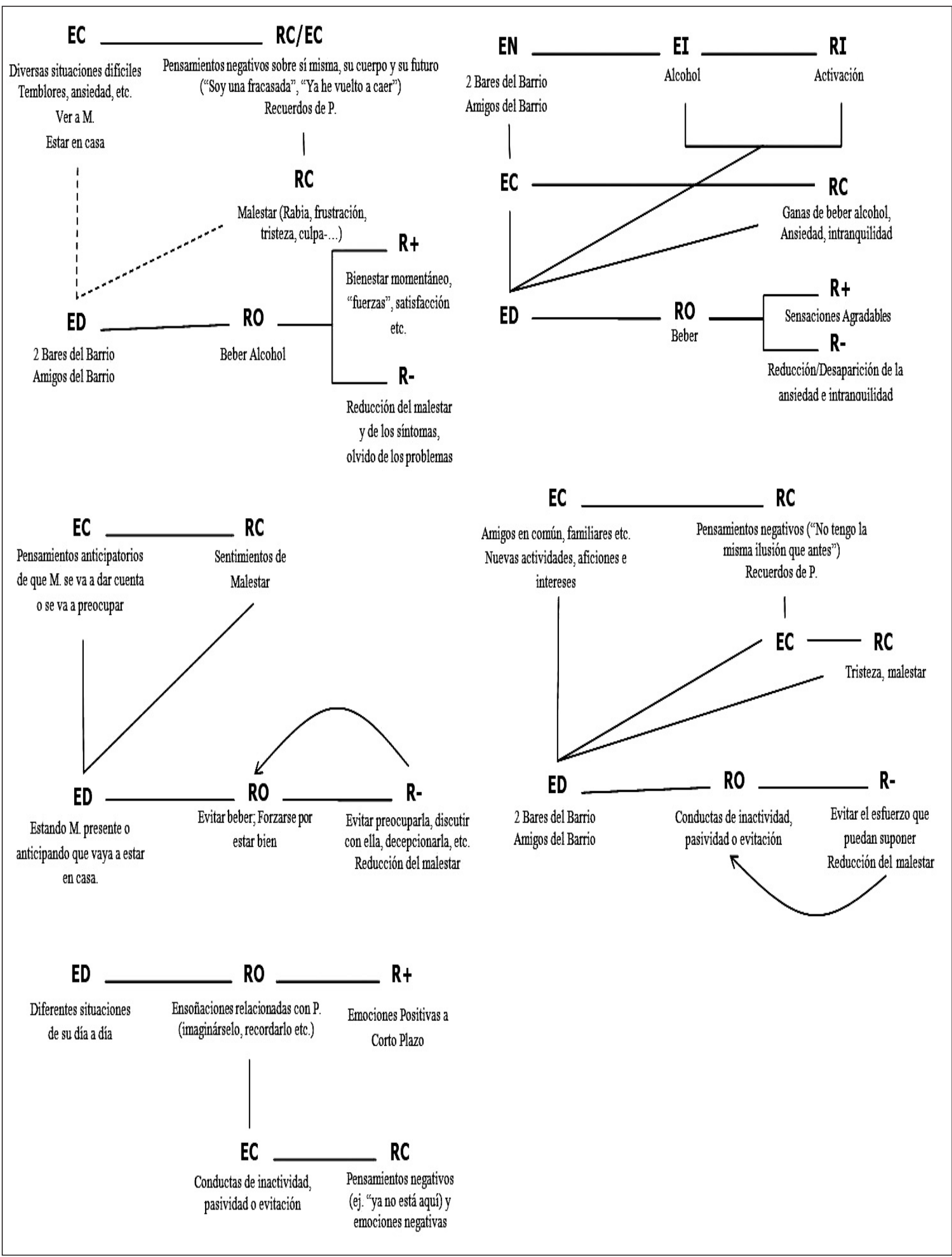


tener muy clara la distinción entre uso, abuso y dependencia, tal y como hacen FernándezMontalvo, J. y Lorea, I. (2005), pues suponen una diferencia en cuanto a la cantidad y frecuencia de alcohol consumido, así como en la funcionalidad de la conducta de ingesta, pudiéndose evolucionar de una categoría a otra hasta existir una adicción a la sustancia. En este sentido, en los casos de abuso del alcohol tratados desde el enfoque psicológico nunca se llega a aislar a la persona, sino que se le dota de las estrategias necesarias para que en los contextos en los que antes consumía mucho alcohol, pueda no hacerlo o lo haga de forma controlada (en esto consisten precisamente las terapias de bebida controlada; Calvo, 1983; Cáceres, 1985). En casos en los que existe una dependencia física, primero habría que pasar por un proceso de desintoxicación para luego pasar a programas de bebida controlada, salvo si hay problemas de salud asociados (en este caso serían preferibles los programas de abstinencia total, que persiguen el objetivo de evitar que la persona vuelva a consumir). De acuerdo con FernándezMontalvo y Lorea (2005), los programas de tratamiento constan habitualmente de cuatro fases específicas: fase de motivación para el cambio (se trata de lograr una mayor implicación en la terapia a través del aumento de la conciencia sobre las consecuencias de la bebida, los beneficios de la abstinencia y las posibilidades de recuperación); fase de desintoxicación (para lograr un periodo mínimo de abstinencia, eliminándose la dependencia físico-química -a través de un control estimular, programa de actividades y/o conductas incompatibles con la bebida, instrucciones de autocuidado, técnicas para el control de la activación y, en casos necesarios, reestructuración cognitiva-) (Peck, 1981); fase de deshabituación (con el fin de eliminar la dependencia psicológica -las ganas de beber y el recuerdo selectivo de los aspectos positivos de la bebida- y normalizar la vida de la persona a través de la eliminación de la función evocadora del consumo que tienen ciertos estímulos y de la creación de nuevos hábitos mediante una exposición gradual a aquéllos y el recordatorio de los efectos negativos del consumo) y una fase de rehabilitación (en la que se previene la aparición de recaídas). En caso de producirse algún consumo, se han de identificar las razones desencadenantes (distinguiendo una caída de una recaída) y se inicia de nuevo el proceso.

\section{Modelos de tratamiento de la depresión}

La depresión se caracteriza por un bajo estado de ánimo general de la persona que suele cursar con pérdida de apetito, trastornos del sueño, pérdida de energía y apatía. En los casos más extremos, la persona puede llegar a cometer el suicidio. Suele ser más frecuente en mujeres que en hombres y presenta un alto nivel de comorbilidad con trastornos de ansiedad (Vallejo y Gastó, 2000). Los comportamientos problemáticos los constituyen los pensamientos, las emociones y las conductas que presenta la persona deprimida, todos ellos interrelacionados.

Una de las causas más importantes que explica la depresión es la existencia de pensamientos irracionales o distorsionados. Estos pensamientos están especialmente relacionados con una visión negativa de uno mismo, el mundo y el futuro y conllevan errores a la hora de procesar la información (Beck, 2002; Ellis y Grieger, 2000; Sanz y Vázquez, 1999). Estos pensamientos generan emociones negativas y falta de ganas de hacer cosas, lo que explicaría, en parte, el bajo estado de ánimo. Otro factor relacionado con el bajo estado de ánimo es la baja tasa de actividades gratificantes que presenta la persona. La reducción de actividades supone una pérdida de reforzadores, entre ellos sociales, generadores de emociones positivas, lo que provoca, a su vez, que el estado de ánimo de la persona empeore y dificulte aún más la realización de actividades.

La intervención en esta problemática se basa en una programación de actividades, basada en la relación existente entre el nivel de actividad y el estado de ánimo (de tal manera que se introducen elementos evocadores de emociones positivas, distractores de pensamientos negativos, etc.). La programación de actividades se suele planificar junto con autoinstrucciones dirigidas a facilitar la puesta en marcha de las mismas y junto con los auto-refuerzos por haberlas realizado (Oblitas, 2009). Por otro lado, también se hace uso de técnicas cognitivas consis- 
tentes en la modificación de los pensamientos inadecuados que presenta la persona, haciéndole ver las consecuencias de ese modo de pensar, los errores cometidos y los beneficios de aprender a pensar de una manera más racional y ajustada a la realidad. La modificación se consigue a partir de la técnica del debate, estableciendo los pensamientos como hipótesis en lugar de verdades absolutas y la comprobación de las mismas, pudiéndose llevar a cabo experimentos conductuales. Este proceso es un moldeamiento, por el cual los pensamientos alternativos, cada vez más cercanos a los adecuados, se van consolidando a través de su reforzamiento, mientras que los irracionales son castigados o extinguidos (Froján, Montaño, Calero y Ruíz, 2011). Dependiendo del caso, puede ser adecuado incluir un entrenamiento en la parada de los pensamientos que generan emociones negativas, de tal manera que eliminando el elemento evocador, la emoción negativa no aparece.

\section{Tratamiento}

En el caso de C., el tratamiento consistió en la aplicación de varias técnicas derivadas del análisis funcional específico del caso. Dado que el tratamiento se llevó a cabo de manera ambulatoria, fue necesario recurrir a personas del contexto de C. explicando lo fundamental de su colaboración y la manera de proceder en cada momento. Como se mencionó anteriormente, los objetivos clínicos fueron:

1. Eliminación del consumo de alcohol. Aunque inicialmente el deseo de C. era beber 1 o 2 copas al mes, finalmente se decidió optar por la abstinencia total debido a los problemas físicos que ya presentaba la cliente (sobrepeso, hígado graso, haber recibido quimio y radioterapia, problemas respiratorios, etc.), consumo de tabaco y problemas económicos, así como la medicación que estaba tomando (antidepresivos, ansiolíticos y broncodilatadores). Para esta decisión también se consultó la bibliografía existente sobre el tema (Echeburúa, 1986; 1993 y Echeburúa y Corral, 1988). Con este fin se plantearon los siguientes objetivos terapéuticos: a) Eliminar la dependencia física. Además de ser el primer paso para la consecución del objetivo, se eliminó uno de los estímulos discriminativos de beber, que eran los propios síntomas asociados a la abstinencia. Se informó a la cliente sobre el uso, abuso y dependencia del alcohol, así como de las características del síndrome de abstinencia y del tratamiento. También se llevó a cabo un programa de actividades incompatibles con la conducta de beber alcohol (mediante un proceso de moldeamiento con el que, partiendo de una lista con posibles actividades gratificantes, la cliente empezó a introducirlas aumentando progresivamente su nivel de actividad, para lo cual también se la entrenó en autoinstrucciones para evitar que estuviera pendiente de si disfrutaba o no de las mismas). El control estimular consistió en evitar que C. entrara en contacto con situaciones y/o personas desencadenantes de la conducta de beber. Asimismo, se reforzó la conducta de abstemia mediante control telefónico y refuerzo contingente en dos momentos estipulados del día a través de un mensaje de texto con verbalizaciones positivas con función de refuerzo (llevado a cabo por la terapeuta). Por último, se le enseñó la respiración controlada para poder controlar la ansiedad derivada de la abstinencia y se reestructuraron semánticamente algunas ideas relacionadas con la bebida, el seguimiento del tratamiento así como con un posible futuro consumo.

b) Eliminar la dependencia psicológica. Para ello se produjo un cambio en la función de algunos estímulos. Los bares, las reuniones familiares, los pensamientos asociados a malestar y la gran cantidad de tiempo libre dejaron de funcionar como estímulos discriminativos de la conducta de beber para discriminar conductas incompatibles con el consumo de alcohol: consumo de bebidas no alcohólicas, aplicación de estrategias para la eliminación de pensamientos asociados a malestar y realización de acti- 
vidades gratificantes. Se llevaron a cabo exposiciones graduales en vivo y controladas a los estímulos que en C. desencadenaban la conducta de consumir alcohol con el objetivo final de que pudiera estar en presencia de los mismos sin beber, emitiendo otra conducta incompatible. Hay que tener en cuenta, tal y como demuestran los estudios de McCrae, Scales y Siegel (1987), que los procesos psicofisiológicos asociados a la pérdida de control pueden ser condicionados a estímulos situacionales y, del mismo modo, extinguidos tras una exposición sistemática a los mismos sin la necesidad de administrar ninguna droga. En nuestro caso programamos 2 ó 3 exposiciones por semana y algunas se dieron sin programarse previamente pero resolviéndose sin dificultad. Estas exposiciones son importantes en tanto en cuanto se ha demostrado que cuando la persona se expone de manera regular a situaciones de riesgo, siendo capaz de controlar la conducta de ingesta, aumenta el grado de seguridad de la persona sobre sus capacidades de afrontamiento (Laberg, 1990) y se ha constatado que correlaciona altamente con las conductas futuras de abstinencia (Solomon y Annis, 1989). Asimismo, en la prevención de recaídas se distinguió entre caída y recaída (Marlatt y Gordon, 1985), se enfatizaron y recordaron los efectos positivos a medio y largo plazo del abandono del alcohol (Maisto, O'Farrel, Connors, McKay y Pelcovits, 1988) y se entrenó a la cliente en la identificación de elementos de la situación que podían propiciar el consumo, así como en estrategias que podía llevar a cabo para afrontar esa situación, pues el recuerdo selectivo de los efectos positivos de la bebida, combinados con una situación de alto riesgo, constituyen uno de los mayores riesgos de recaída (Hodgson, 1991).

2. Mejora del estado anímico. Se planteó este objetivo para facilitar el éxito del anterior y para mejorar el estado global de la cliente con el fin de, en un momento posterior y en caso de ser necesario, poder abordar las restantes demandas (descontento con el físico, consumo excesivo de tabaco, desorganización de los horarios y hábitos alimenticios, etc.). En este sentido, se plantearon los siguientes objetivos terapéuticos:

a) Incremento de estímulos condicionados asociados a emociones positivas. Esto se consiguió mediante un aumento en la actividad general de $\mathrm{C}$. (aumento de la tasa de reforzamiento positivo) a través de una planificación de actividades (explicándose la relación entre el nivel de actividad y el estado de ánimo, así como pidiendo registros de las actividades realizadas) y un entrenamiento en autoinstrucciones (para iniciar la realización de las tareas y contribuir a su mantenimiento). La lesión en el hombro y la reticencia inicial a salir del barrio no produjo ninguna interferencia para la realización de actividades; la cliente accedió a salir del barrio sin problemas y tan solo hubo que sustituir una de las actividades (yoga) por otra que no producía molestias en el hombro. Así mismo cabe decir que la posterior eliminación del consumo de alcohol, C. también contribuyó al aumento del número de verbalizaciones positivas.

b) Reducción de estímulos condicionados asociados a emociones negativas. Esto se consiguió mediante una reducción de verbalizaciones negativas mediante la técnica de parada de pensamiento (combinada con las tareas distractoras) y la reestructuración cognitiva de creencias irracionales relacionadas con la bebida (ej.: "por una copa no pasa nada"), consigo misma (ej.: "mi vida es un desastre", "no sé qué voy a hacer con mi vida", etc.), con la muerte de su marido (ej.: "sin mi marido nada va a ser igual que antes", "no voy a superarlo nunca", etc.).

Pese a que C. presentaba otras áreas problemáticas (consumo excesivo de tabaco, malestar o insatisfacción con su cuerpo, problemas de sueño y sobre- 
peso), se decidió abordar los objetivos que resultaron prioritarios tanto para la cliente como para la terapeuta, con la posibilidad de ir abordando el resto de objetivos más adelante siempre que la cliente lo demande.

\section{Resultados}

Nuestro propósito en este artículo es analizar el cambio producido en este caso a raíz de la intervención conductual. En la línea con lo que dice Valero (2009) sobre la vertiente científica de la práctica clínica, "el clínico debe evaluar su propio trabajo utilizando métodos empíricos para determinar su efectividad y calidad (...) y puede informar de sus hallazgos a la comunidad científica". Por ello hemos procurado ser lo más rigurosas posibles en los análisis y conclusiones. Procedimos a identificar y operativizar las medidas de cambio de la manera en que a continuación se especifican, con el objetivo de contrastar el posible cambio debido a la intervención (Froján, Montaño y Calero, 2006). Para ello se dividió el tratamiento en dos mitades, estableciendo el punto de corte en la décima sesión por tratarse del valor de la mediana. En este sentido se analizaron las variaciones en las medi- das de cambio entre ambas mitades de la terapia, hipotetizando que en la segunda mitad de la intervención se produciría un aumento de las conductas consideradas positivas (aquéllas que reflejan un éxito de la intervención) y una reducción de las conductas consideradas negativas (aquéllas que se pretendieron reducir o eliminar) respecto a la primera mitad.

\section{Grado de implicación con la terapia}

Como es sabido, uno de los factores que determinan y ayudan a predecir el éxito terapéutico es la implicación del cliente en la terapia, que se ha operativizado atendiendo a las siguientes medidas:

a) Realización de las tareas para casa y/o cumplimiento de las pautas de tratamiento establecidas entre sesiones: Puesto que la tasa de incumplimiento fue muy alta, recurriendo a muchas excusas para justificarlo, hubo que tomar medidas de control más estrictas (hacer depender la siguiente sesión del cumplimiento o no de las tareas o traer las tareas como único criterio para considerarlas realizadas). Los resultados obtenidos, representados en la

Figura 1. Gráfico de la realización de las tareas para casa y/o cumplimiento de las pautas de tratamiento establecidas entre sesiones. El eje X representa el número de sesiones, mientras que el eje Y representa el porcentaje de tareas realizadas en cada sesión

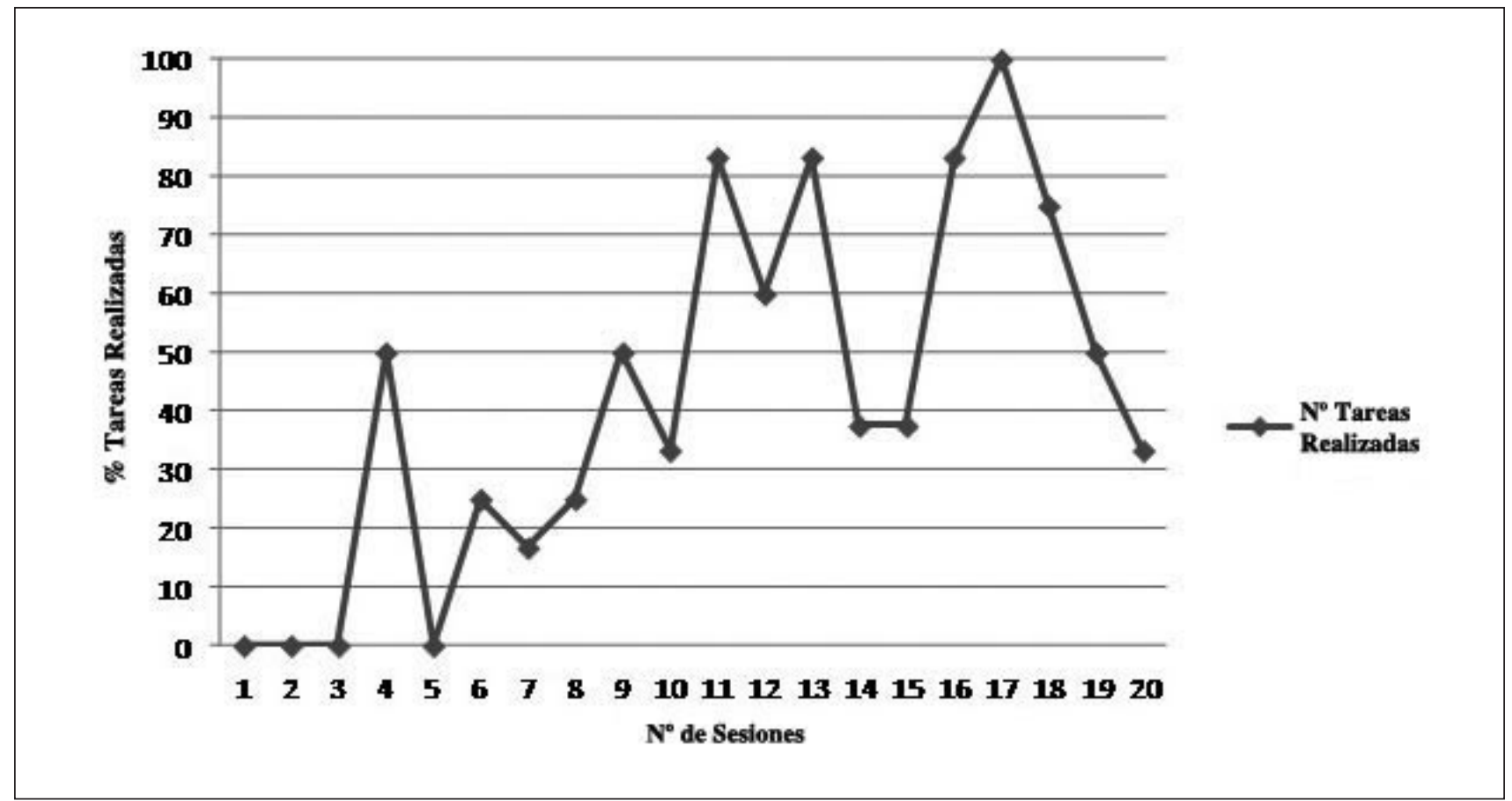


Figura 1, indican un aumento del cumplimiento en la segunda mitad de la intervención (una media de $64,3 \%$ de tareas hechas en la segunda mitad frente a una media del $22,2 \%$ en la primera, como muestra la Figura 1). Esto se podría tomar, pues, como un indicador del incremento de la implicación en la terapia.

b) Aprender y conocer los objetivos a seguir, el sentido del tratamiento, por qué se aplican las técnicas seleccionadas, etc.: Se espera que cuanto mayor sea la implicación, mayor será la atención y por tanto la comprensión de las pautas. Antes de la décima sesión, C. preguntó y se mostró impaciente por avanzar, no entendiendo por qué no se empezaba con la intervención en la bebida cuanto antes. Incluso quiso intentarlo por sus propios métodos. Inicialmente tampoco entendía el objetivo que se perseguía con la respiración. En lo que a la segunda mitad del tratamiento se refiere, sólo hubo dos ocasiones en las que $\mathrm{C}$. tuvo dificultades para entender y/o recordar ciertos procedimientos (ej.: el objetivo de enumerar las situaciones que le habían resultado difíciles, las estrategias adquiridas hasta el momento, las consecuencias de la bebida, etc.). Por otra parte, en la pri- mera mitad del tratamiento $\mathrm{C}$. dio muestras de incomprensión o dudas en un $66,67 \%$, mientras que en la segunda mitad sólo un 33,33\%, infiriéndose de ello una mayor comprensión de todo el proceso terapéutico que puede relacionarse a su vez con una mayor implicación en el mismo. Todo ello se infirió por el tipo de verbalizaciones de la cliente (en forma de preguntas, dudas, afirmaciones incorrectas -errores-, etc.).

c) Motivación por la terapia: Dado que la "motivación" es un constructo y, como tal, no es observable, se infiere siempre de la conducta manifiesta. De acuerdo con la propuesta de Froján, Alpañés, Calero y Vargas (2010), consideramos la motivación como un cambio en el ambiente o en el organismo que altera las funciones de los estímulos y los parámetros de una respuesta aprendida, sin verse implicados procesos clásicos u operantes de aprendizaje. Por lo que aquí nos referimos a aquellas conductas dirigidas a continuar con el tratamiento y que se caracterizan por una alta frecuencia (ej.: verbalizaciones relacionadas con el hecho de continuar la terapia, con las consecuencias negativas de la bebida, etc.) e intensidad (en

Figura 2. Gráfico sobre la motivación por la terapia. En el eje X se representan las diferentes sesiones, mientras que en el eje Y queda representado el número de verbalizaciones o acciones que denoten una alta o baja motivación

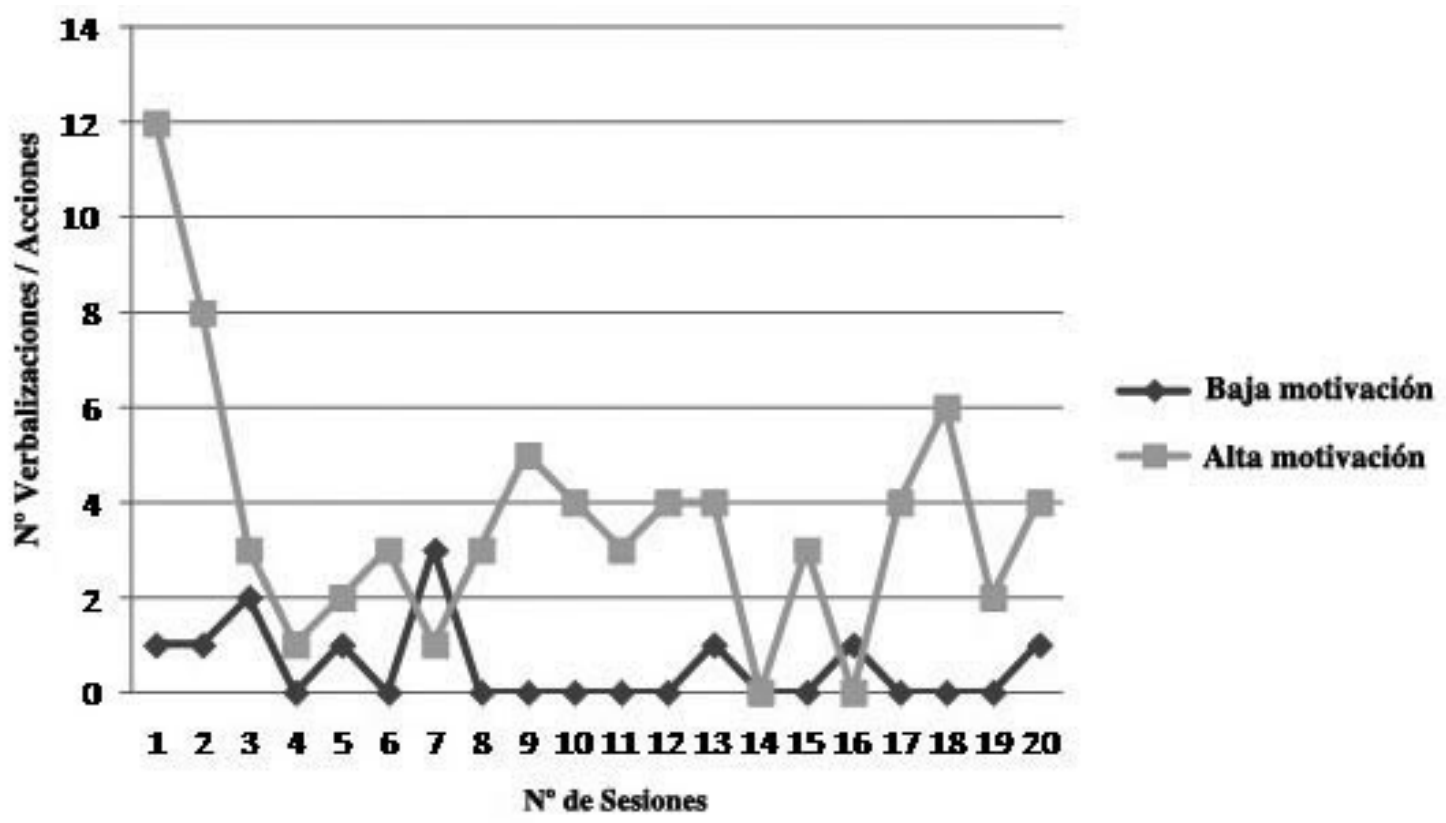


función del tipo de verbalizaciones que emitía la cliente). Por otra parte, se han incluido aquí todos aquellos cambios o conductas que la cliente llevó a cabo sin ser precedidos por instrucciones o pautas de tratamiento (siempre y cuando no fueran en contra de las mismas o perjudicaran la intervención). Conviene tener presente que la terapeuta discriminó muchas de las verbalizaciones que tenían que ver con aspectos negativos de la bebida y con aspectos positivos de la abstinencia, pues esto formaba parte del tratamiento. Los resultados en relación a los cambios en esa variable se pueden observar en la Figura 2.

\section{Ingesta o consumo de alcohol}

La modificación de la conducta de ingesta se ha medido a través de varios parámetros. Por un lado, se ha tenido en cuenta el consumo diario (en días de consumo y número de copas), medido a partir de autorregistros. La superación de la dependencia fisiológica se ha valorado a través de la cuantificación de días de no consumo y la psicológica a través de las verbalizaciones acerca de las ganas de consumir y del número de exposiciones a los estímulos desencadenantes de la conducta de beber sin consumo. Antes de empezar la intervención sobre el consumo (en la Sesión 8), C. redujo la ingesta por iniciativa propia. Una vez comenzado el control estimular, entre las Sesiones 8 y 9 consumió en dos ocasiones por no haber evitado la exposición a dos situaciones en las que el alcohol estaba disponible. La fase de desintoxicación se consideró superada tras no haber consumido durante 3 semanas. El último día en que consumió alcohol fue 51 días después de comenzada la intervención (entre las Sesiones 8 y 9), manteniéndose así hasta el final del tratamiento (de la Sesión 9 hasta la 20). Los cambios producidos respecto al consumo de alcohol se pueden consultar en la Figura 3. A partir de la Sesión 12 se inició la fase de eliminación de la dependencia psicológica. Para ello se realizaron 16 exposiciones graduales programadas a bares (de menor a mayor familiaridad y, por tanto, de menor a mayor asociación con la conducta de beber) con ayuda de los coterapeutas (su hija y su hermana). Estas exposiciones debían realizarse con la frecuencia media de dos por semana (bien fuera con su hija o con su hermana en función de su disponibilidad). En 10 ocasiones se produjeron también exposiciones no programadas. Tanto unas como otras se realizaron con éxito. Con respecto a las ganas de beber, si bien en la segunda mitad se produjo un aumento en el

Figura 3. Gráfico del consumo de alcohol. El eje X representa los días anteriores y posteriores a la fecha de inicio del control estimular (día 1 de agosto). En el eje Y se representa el número de copas consumidas en esos días

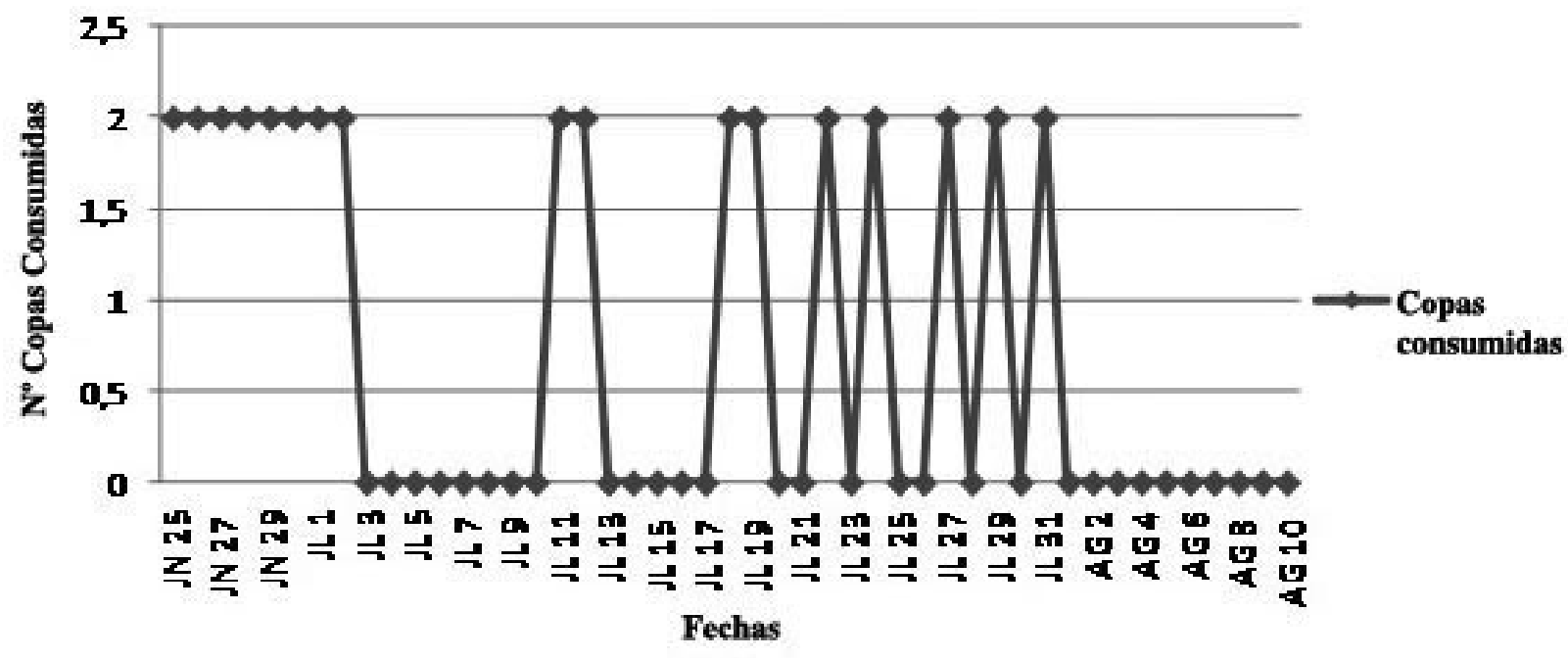


número de verbalizaciones respecto a la primera (un $62,5 \%$ frente a un $37,5 \%$ ), en la segunda mitad todas las verbalizaciones se refirieron a un deseo puntual y no a un deseo generalizado como en la fase anterior.

\section{Estado de ánimo:}

Bajo esta categoría se contemplan tres tipos de variables: 1) la expresión verbal de emociones, dividiéndose en "verbalización de emociones positivas" (ej. "me encuentro anímicamente mejor", "ya no está tan apática") y "verbalización de emociones negativas" (ej. "me siento desesperanzada porque no voy a recuperar a mi marido ni voy tener las mismas ilusiones que tenía cuando estaba con él”); 2) la expresión no verbal de emociones positivas y negativas que la cliente mostraba de manera espontánea en las sesiones a través de gestos, muecas, rictus facial, etc. (ejemplos de "emociones positivas" serían la sonrisa y ejemplo de "emociones negativas" sería el llanto); 3) ganas de hacer cosas, que se ha operativizado a través de las verbalizaciones que indicaban "falta de ganas" (reflejaban desgana, esfuerzo, pereza, desánimo, falta de motivación e iniciativa para hacer cosas -ej.: "he perdido interés por todo", "no tengo rumbo en mi vida"-) y "ganas" (aquéllas que reflejaban anticipación del refuerzo tras la actividad, motivación e iniciativa para hacer cosas, etc. -ej.: "me encuentro con más ganas de hacer cosas", "salí con mi hija a tomar el aperitivo y estuvimos tan a gusto que hemos pensado hacerlo más veces").

Para medir el grado de cambio se han comparado las frecuencias de cada subcategoría ("positiva"/ "negativa") dentro de cada una de las categorías básicas entre las dos mitades de la intervención. En cuanto a las muestras no verbales del estado anímico, puesto que sólo la terapeuta ha tenido acceso y no se ha llevado un registro minucioso, se ha realizado un análisis cualitativo, con base en el cambio percibido por la psicóloga a lo largo de la intervención. Los resultados encontrados han sido un aumento del $78 \%$ en la verbalización de emociones positivas en la segunda mitad del tratamiento respecto a la primera, al tiempo que se reduce en un 86\% la verbalización de emociones negativas. Estos datos se muestran en la Figura 4. La expresión no verbal de emociones negativas durante las sesiones fue igualmente disminuyendo, siendo esta reducción especialmente notable en la conducta de llanto, muy frecuente al inicio del tratamiento. De forma paralela, fue incrementándose la expresión no verbal de emociones positivas (gesto más relajado, sonrisa,

Figura 4. Gráfico del estado de ánimo. El eje X representa las dos mitades de tratamiento, mientras que el eje Y refleja el número de verbalizaciones (en datos absolutos) relacionadas con emociones positivas o negativas

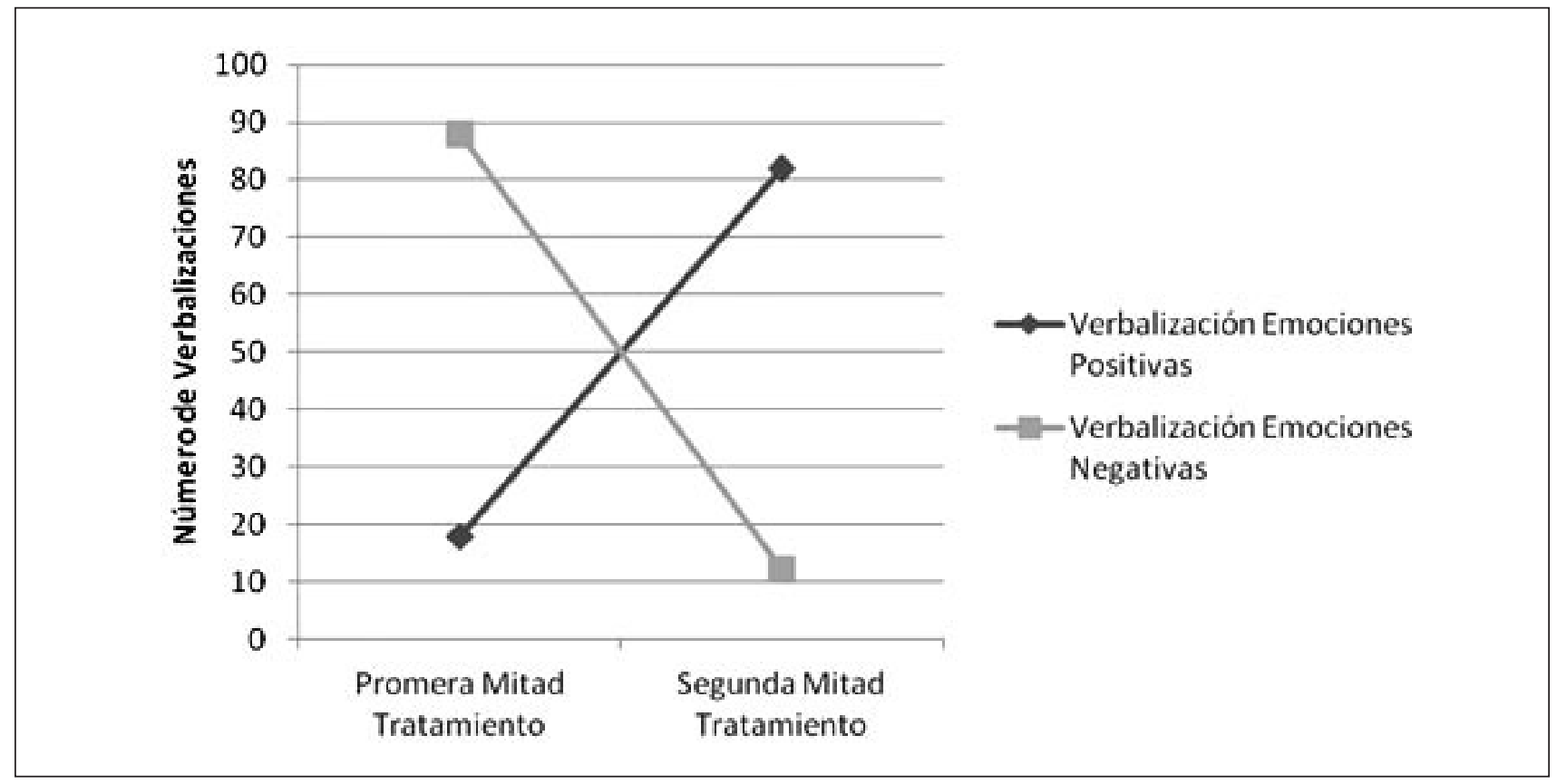


etc.). Las verbalizaciones relativas al impulso y a las ganas de hacer cosas se incrementaron en un 33\% y se redujeron en un $94 \%$ las expresiones verbales de desmotivación, apatía y falta de ganas, como se puede observar en la Figura 5.

\section{Nivel de Actividad:}

En la línea que defiende la Activación Conductual (AC), se decidió hacer un programa de actividades encaminado a lograr que la cliente aprendiera a organizar su vida y a cambiar su entorno para que se restableciera su contacto con fuentes de reforzamiento positivo (Barraca, 2010), así como a facilitar el logro de la abstinencia. Algunas de las medidas fueron la programación de objetivos a medio y largo plazo para su día a día cotidiano, el reforzamiento de conductas de contacto social o la realización de actividades gratificantes. En este sentido, se tuvieron en cuenta dos criterios para operativizar el cambio: 1) tipo de actividades que realizaba (atendiendo a la variedad de actividades), y 2) nivel de satisfacción que su realización le reportaba. Con respecto a la primera categoría, se estableció una división en cuanto al carácter de la actividad: a) actividad gratificante (actividades con carácter organizado que C. iba incluyendo a su día a día como actividad placentera, con carácter puntual o con un horario de realización establecido, pero que no podían considerarse parte de la rutina diaria, pese a que pudieran tener periodicidad -ej.: talleres, cursos, ir a comprarse un libro, etc.-) y b) rutinas diarias (actividades que llevaba a cabo a lo largo del día por formar parte de las tareas cotidianas - ej.: paseos, entretenerse con el ordenador, tareas domésticas, lectura, etc.-). Se excluyeron de esta categoría aquellas actividades que C. realizaba con otras personas, incluyéndose éstas en el siguiente apartado (relaciones sociales). En cuanto al grado de satisfacción, lo que se tuvo en cuenta fue el tipo de verbalizaciones que emitía la cliente en relación a las actividades realizadas, dividiéndose éstas en positivas (reflejaban agrado, disfrute -ej.: "he disfrutado mucho tomando el aperitivo con mi hija"-) y negativas (expresaban desagrado, ausencia de disfrute -ej.: "siento que lo que hago no me ilusiona igual, no estoy contenta y no disfruto"-).

Para medir el grado de cambio se ha establecido una línea base en cuanto al nivel de actividad inicial y se ha comparado la variedad de actividades (número de nuevas actividades) que se han incorporado a la línea base en ambas mitades de la intervención. Para ello se han utilizado los regis-

Figura 5. Gráfico de las verbalizaciones sobre las ganas de hacer cosas. El eje X muestra tanto la primera como la segunda mitad de tratamiento y el eje $\mathrm{Y}$ el número de verbalizaciones de ganas o falta de ganas de hacer cosas

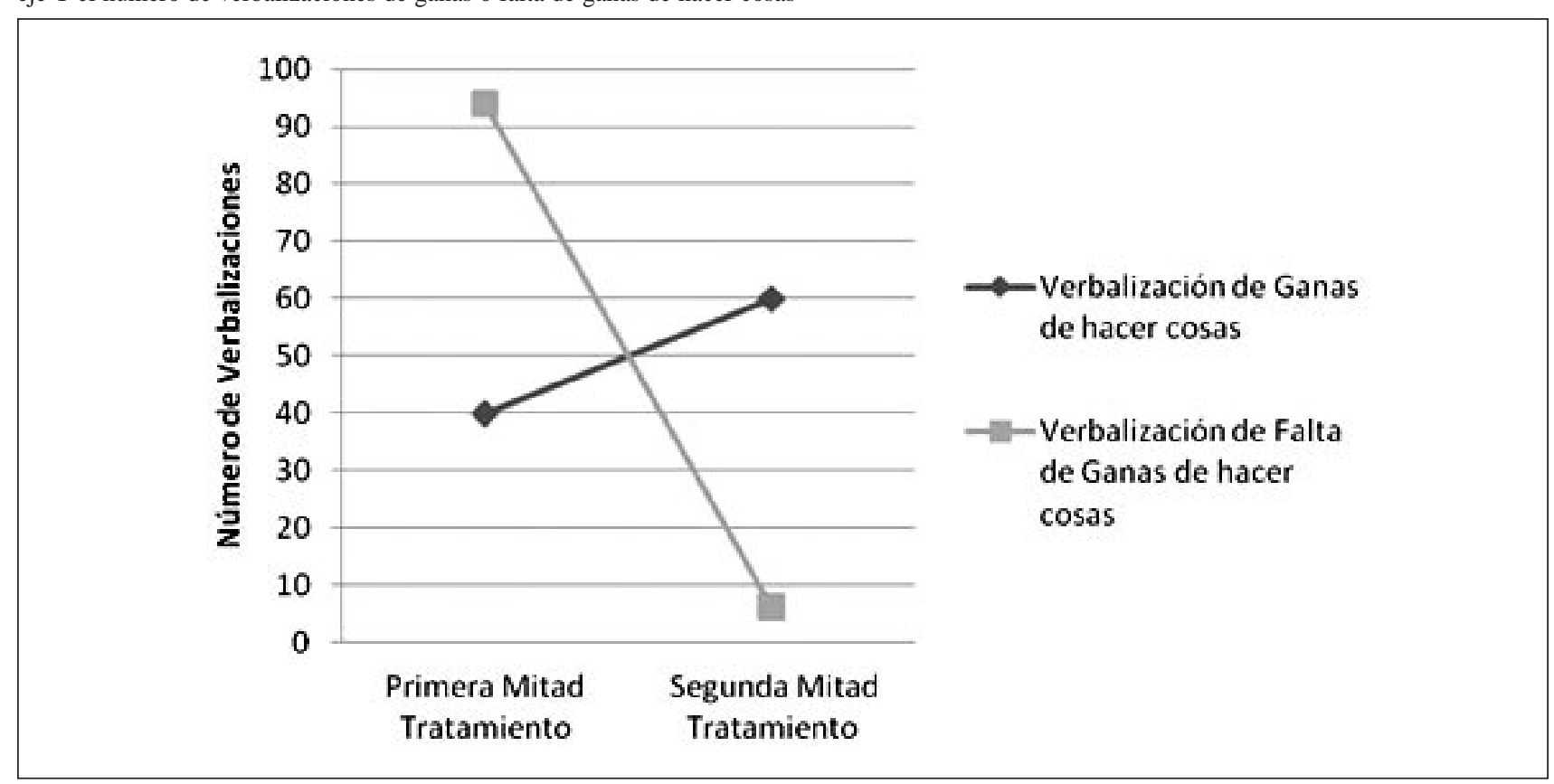


tros que se le fueron encargando a la cliente. Asimismo, se ha calculado la actividad semanal media de la cliente en cuanto a "actividades gratificantes" y se ha comparado este nivel de actividad semanal medio entre ambas mitades de la intervención. En el caso de las rutinas diarias nos hemos tenido que limitar a hacer una análisis cualitativo, ya que en esta categoría el incremento no ha sido tanto en tipo de nuevas rutinas (ya que los quehaceres del día a día seguían siendo los mismos) sino en variedad (dentro de la misma tipología se dedicó tiempo a tareas nuevas o poco frecuentes) o en tiempo dedicado. Por ejemplo, dentro de las rutinas domésticas $\mathrm{C}$. buscó momento para organizar la casa, organizar armarios y papeles, poner mayor empeño y dedicación en cocinar; por otro lado, empezó a dedicar más tiempo a leer y a pasear, etc. Todo esto supone un cambio respecto a la línea base inicial. En cuanto a la cantidad de verbalizaciones "positivas" y "negativas", se ha comparado la frecuencia de ambos tipos de verbalizaciones entre la segunda y la primera mitad de la terapia.

Hay que especificar que el número de actividades nuevas supone una aproximación extraída de los registros de la cliente, por lo que habría que contar con que pueda faltar información en tanto en cuanto no aportó todos los registros o éstos fueron incompletos. Para realizar los cálculos, se contó con el total de registros aportados. En cualquier caso, los datos (reflejados en la Figura 6) muestran un incremento de un $75 \%$ en la actividad entre la primera y la segunda mitad de la terapia, ya que además muchas de las actividades consideradas gratificantes eran de carácter periódico (talleres de varios días en semana, a los que raras veces faltaba). En cuanto al nivel medio de actividad semanal, durante la primera mitad de la intervención la actividad gratificante era inexistente y posteriormente se fue incrementando hasta alcanzar un nivel medio de 2 o 3 actividades semanales (si se contabiliza sólo desde el momento en el que se iniciaron los talleres, la media de actividad asciende a 3-4 actividades por semana). Por otra parte, las rutinas y actividades cotidianas que va incorporando a su día a día también aumentaron en variedad y en tiempo dedicado, dedicando cada vez más tiempo a organizar, cocinar, salir a la calle para hacer recados, etc. Especialmente en la segunda mitad de la intervención se incrementó el tiempo dedicado a pasear, a la lectura, a ver películas todas las semanas e incorporó una rutina para ella muy satisfactoria, como era desayunar en una cafetería los

Figura 6. Gráfico del nivel de actividad. El eje X representa las diferentes sesiones (la primera mitad de la intervención abarca de la Sesión 1 a la Sesión 10, mientras que la segunda mitad de la Sesión 11 a la Sesión 20). El eje Y corresponde al número total de actividades gratificantes

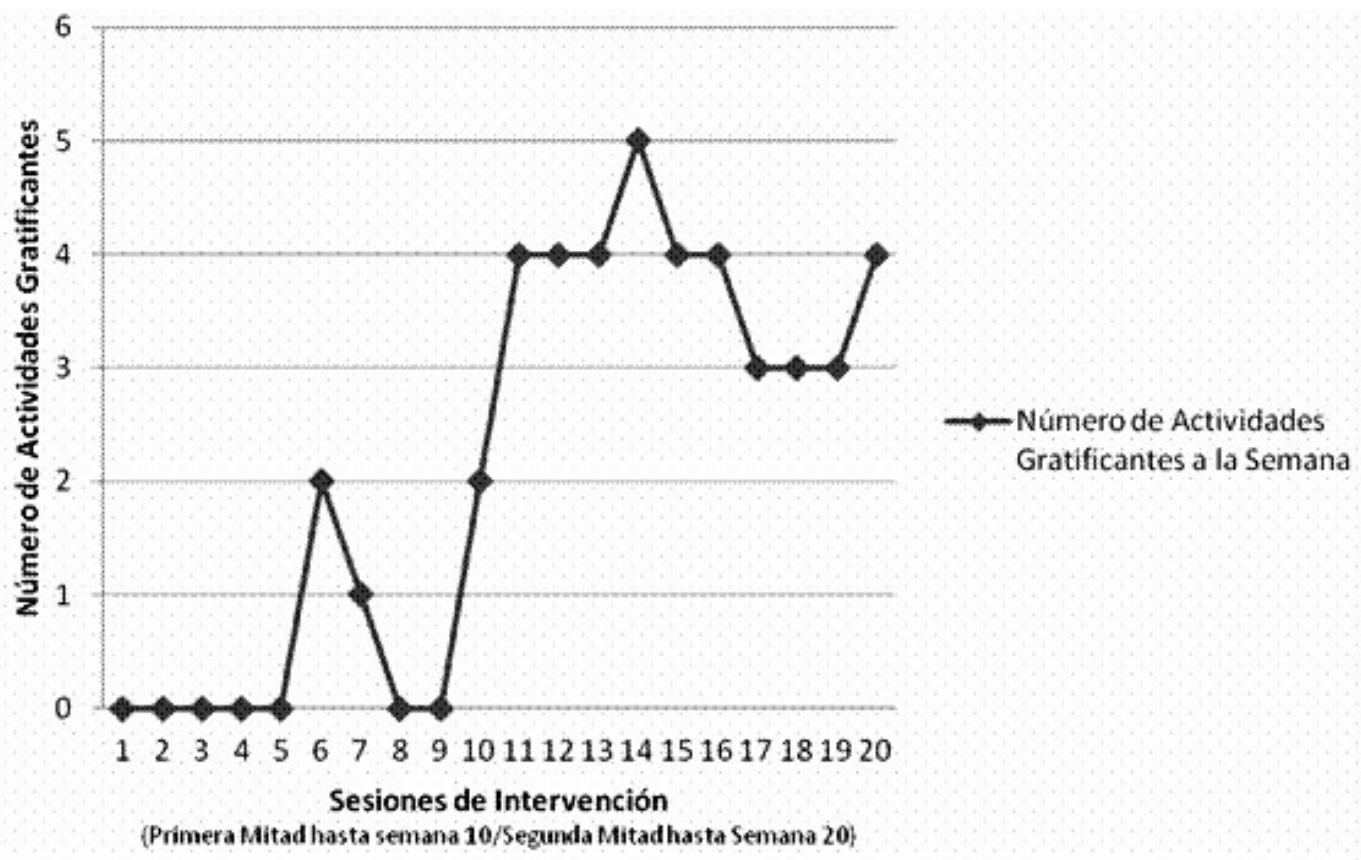


domingos y leer allí el periódico. Respecto al grado de satisfacción con las actividades, el número de verbalizaciones positivas en relación a la actividad aumentó en un $89 \%$ entre ambas mitades de la intervención y se redujo en el 100\% el número de quejas relacionadas con la realización de actividades. En la segunda mitad C. tan sólo emitió una queja relativa a los dolores musculares, que le llevó a sustituir el taller de Yoga por uno de Autoestima. No obstante, esto no se ha contado como queja sobre la realización de actividades, puesto que la actividad no le agradaba completamente y fue sustituida por otra que le era más gratificante.

\section{Relaciones Sociales:}

Esta categoría incorpora tres subapartados en los que se que han tenido en cuenta: 1) el tipo de conductas que emitía la cliente: divididas en conductas de evitación (del contacto social -ej.: "soy capaz de cruzarme de acera con tal de no hablar con alguien"-) y conductas de aproximación (buscaban o procuraban el contacto social -ej.: "he estado hablando con amigos varios días en semana”); 2) eventos de contacto social: contempla la materialización del contacto con una/s persona/s para realizar alguna actividad gratificante (siendo importante que el objetivo del evento social sea "gratificante", pues no se han contemplado como tales las exposiciones a la bebida -lo que sí se ha tenido en cuenta es si se aprovecha esa cita para realizar además alguna actividad placentera-; sí se han incluido aquí los eventos familiares a los que acudió, ya que en el momento de iniciar la terapia, C. tendía a evitar estas situaciones); 3 ) grado de satisfacción: se ha operativizado a través de verbalizaciones "negativas" (expresaban desgana, pereza o coste -ej.: "siempre he sido una persona a la que le ha gustado estar con gente, pero ahora no tengo ilusión”-) y "positivas" (expresaban disfrute - ej.: tras quedar con sus amigas para comer, comenta "lo pasamos muy bien, charlando y paseando por la zona”-) que la cliente emitió al respecto de los contactos sociales que mantenía. Toda esta información se obtuvo a partir de entrevistas con la cliente y con las coterapeutas.

Los análisis (reflejados en la Figura 7) indican que se redujeron totalmente las conductas de evitación del contacto (C. ya no rehuía a la gente por la calle, no rechazaba llamadas y no evitaba los

Figura 7. Gráfico de las relaciones sociales. El eje X ilustra las mitades de tratamiento, mientras que el eje Y refleja el número de conductas de evitación y de aproximación al contacto y el número de eventos sociales

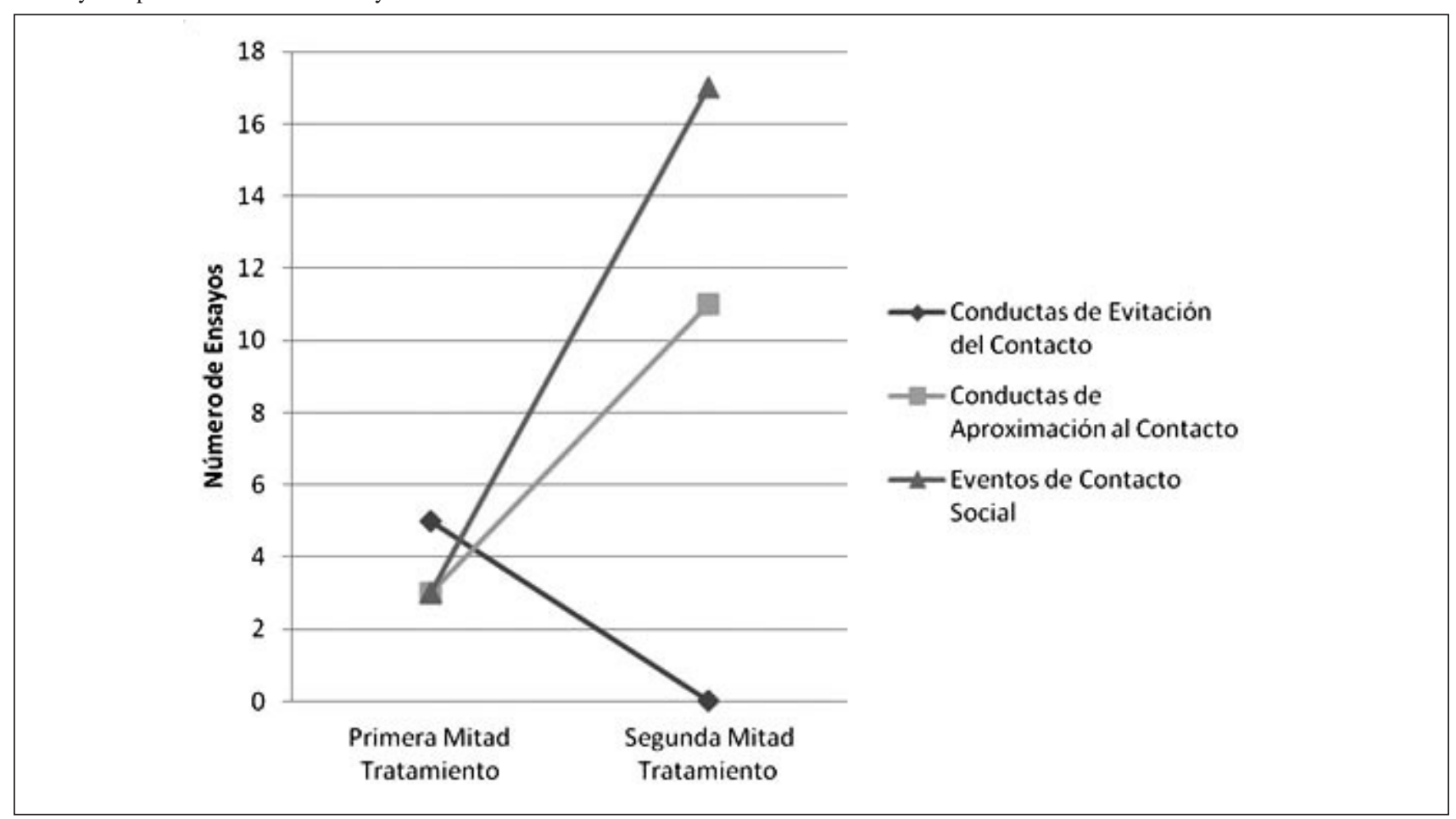


eventos familiares), así como se incrementaron en un $73 \%$ las conductas de aproximación (C. tomaba la iniciativa de llamar por teléfono a los amigos o si se encontraba a algún conocido, se acercaba a saludar o compartía una conversación con él). De igual manera, se incrementaron los "eventos de contacto social", que a día de iniciar la intervención eran inexistentes. El nivel de satisfacción en el área social también se incrementó sustancialmente, ya que en el momento de iniciar la intervención sólo existían en su repertorio verbalizaciones negativas y de insatisfacción respecto a los contactos sociales, habiendo desaparecido estas verbalizaciones totalmente en la segunda mitad de la intervención.

\section{Habilidades o estrategias de afrontamiento adquiridas con el tratamiento}

Con este apartado nos hemos referido a la adquisición, por medio de la intervención, de habilidades o estrategias de afrontamiento adecuadas, no presentes anteriormente en el repertorio básico de conducta de C. Hay que tener presente que cuando la cliente describía progresos en este sentido, también emitía verbalizaciones positivas (pudiéndose incluir en su apartado correspondiente); no obstante, se ha decidido no hacerlo para evitar redundancias.

a Habilidades o estrategias adquiridas: Con este apartado hemos medido el grado de éxito con el que $\mathrm{C}$. fue adquiriendo y aplicando las diferentes habilidades aprendidas, entendiendo por "éxito" la consecución del objetivo que se ha perseguido con esa técnica en concreto. Para operativizar el grado de éxito, se ha utilizado una escala subjetiva para cada una de las estrategias entrenadas con valores que oscilan del "3 " al " +3 " en base al grado de dominio de la técnica, de las dificultades encontradas y de las consecuencias positivas o negativas derivadas de su puesta en práctica. Los niveles de esta escala se operativizan en la Figura 8. También hemos tenido en cuenta la fase de la intervención en la que nos encontrábamos en cada momento, ya que entre las Sesiones 8 y 11 se ha considerado un "éxito" el evitar situaciones asociadas con la bebida (ya que pertenecían a la fase de control estimular), mientras que a partir de la Sesión 12 se ha considerado un "éxito" toda exposición a situaciones de riesgo en las que C. no bebió y aplicó las estrategias adquiridas. No obstante, también se han considerado "éxitos" aquellas exposiciones a situaciones de riesgo que, si bien supusieron un incumplimiento en la fase de control estimular, se abordaron con éxito (C. consiguió no beber). En lo que a los resultados se refiere (mostrados en la Figura 8), podemos decir que pese a una caída puntual en las puntuaciones (que coinci-

Figura 8. Gráfico de la adquisición de estrategias. En el eje X se ha representado la totalidad de las sesiones, mientras que en el eje Y se ha contabilizado el grado de éxito con el que C. ha ido adquiriendo y aplicando las diferentes habilidades o estrategias a raíz del tratamiento psicológico, yendo desde el -3 (indicador de fracaso) hasta el +3 (indicador de éxito), pasando por el -2 (serias dificultades para aplicarlas con éxito), por el -1 (dificultades para su aplicación), 0 (indiferencia o ausencia de mejorías o empeoramientos), +1 (dificultades para su aplicación pero con ciertas mejorías) y +2 (mejorías significativas aunque sin suponer un éxito total)

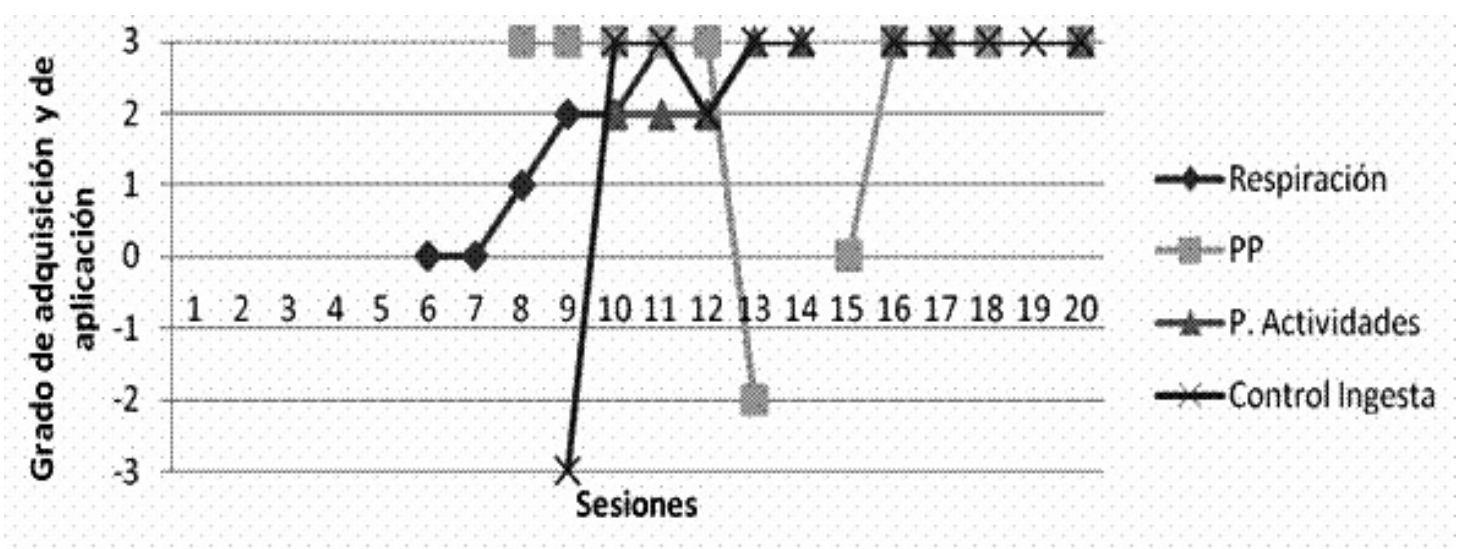


dió con el periodo de Navidades y que se comenta en el apartado Discusión), C. mostró a lo largo del tratamiento una progresiva adquisición de las habilidades (mostrando en todas ellas un nivel " +3 " al final del mis-mo).

b) Generalización de las estrategias adquiridas a otros ámbitos de su vida no directamente relacionados con la conducta-problema: Tal y como muestra la Figura 9, se han generalizado la parada de pensamiento, la respiración controlada y el debate de pensamientos. Algunos ejemplos son el hecho de detener pensamientos relacionados con problemas económicos o familiares, aplicar la respiración controlada cuando se ponía nerviosa en situaciones donde tenía miedo a caerse o al acostarse, o reformular pensamientos irracionales tras acontecimientos negativos. La proporción en que C. ha mostrado una generalización de los aprendizajes (considerando todas las estrategias) en la primera mitad del tratamiento ha sido de un $33,33 \%$, mientras que en la segunda mitad ha sido $66,66 \%$.

\section{Verbalizaciones positivas y negativas:}

En esta categoría se han recogido todas aquellas verbalizaciones de carácter positivo o negativo que C. emitió en sesión en relación a sus problemas actuales en general o al consumo de alcohol, habién- dose excluido aquéllas relacionadas con su estado anímico, el nivel de actividad general y su actividad social. Se han establecido dos subcategorías de análisis de las Verbalizaciones: 1) las relativas a problemas generales presentes en el momento de acudir a terapia (ej.: "te quedas viuda y te mueres de asco" o "estoy comiendo fruta y tratando de guisar sano") y 2) las relativas a la conducta específica de consumo de alcohol (ej.: "soy muy tonta por no ser capaz de aguantar" o "voy a hacer todo lo posible por no volver a caer"). En relación a las últimas, se han excluido las verbalizaciones sobre las ganas de consumir alcohol, tenidas en cuenta en otro apartado. En relación a lo anterior, se ha detectado un incremento del $10,34 \%$ de verbalizaciones negativas en la segunda mitad respecto a la primera. Si bien es verdad que la valoración que $\mathrm{C}$. hacía sobre su propio cuerpo no ha sido objeto de intervención, hemos incluido este apartado para comprobar si se han producido cambios en relación a este tema. En este sentido se ha detectado un decremento de un 33,3\% de este tipo de verbalizaciones. Respecto a las verbalizaciones negativas relacionadas con el consumo de alcohol, se ha visto una reducción del 66,67\% en la segunda mitad con respecto a la primera. Por último, con respecto a las verbalizaciones positivas, se ha obtenido un incremento del $33 \%$ en las verbalizaciones sobre problemas generales y del $83 \%$ en las verbalizaciones sobre la ingesta del alcohol, ambas en la segunda mitad respecto a la primera.

Figura 9. Gráfico de la generalización de las estrategias adquiridas. El eje X representa las dos mitades del tratamiento, mientras que el eje Y ilustra el número de veces que la cliente aplicó las principales estrategias adquiridas (parada de pensamiento, respiración y debate) a otros ámbitos de su vida

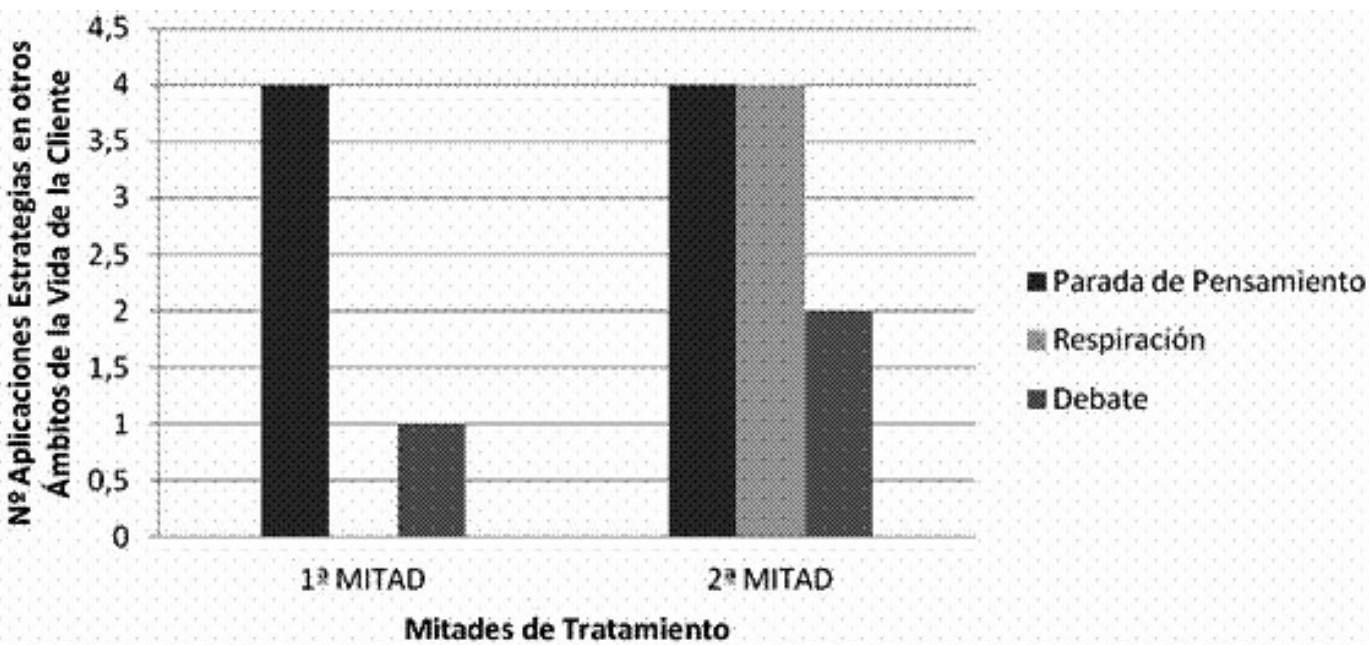




\section{Cambios percibidos por su entorno}

En este apartado nos hemos referido al tipo y frecuencia de verbalizaciones procedentes del entorno más cercano de C. que reflejan la presencia o ausencia de cambios (en sentido positivo o negativo) en su comportamiento, así como a las verbalizaciones de la propia cliente en relación a lo que refirió su entorno, aumentando así nuestro grado de confianza en dicha información. Con respecto a las verbalizaciones del entorno, se han referido muchas más mejorías en la segunda mitad del tratamiento $(81,82 \%$ del total) que en la primera (18,18\% del total). Y en lo que a las verbalizaciones de $\mathrm{C}$. se refiere, también se ha obtenido un $60 \%$ del total en la segunda mitad frente a un $40 \%$ en la primera.

\section{Discusión}

Debemos empezar esta discusión señalando que en nuestro trabajo hemos preferido sustituir el término "alcoholismo" (por las connotaciones médicas de "enfermedad" que tiene) por el de dependencia o adicción al alcohol, entendiendo por ésta un problema conductual (abordable, por tanto, desde el punto de vista psicológico). Lo más característico del enfoque conductual es que considera el problema del alcohol como una pérdida de control con respecto a la bebida, al igual que ocurre con el abuso de otras sustancias. Pero la pérdida de control no deja de ser un problema comportamental, aunque en el tema que nos ocupa con claras consecuencias orgánicas. Esto no quiere decir que "el alcohólico" tenga una enfermedad mental o un problema interno de naturaleza biológica que le haga consumir, sino que son los mecanismos de aprendizaje (clásico y operante) los que hacen que una persona inicie y mantenga su problema de consumo (Seva y Vázquez, 1982; Echeburúa, 1990; Graña y Carrobles, 1991; Echeburúa, 1993).

Antes de pasar a discutir los resultados obtenidos, es importante insistir en el hecho de que la información que se presenta se ha extraído del análisis de las grabaciones de todas las sesiones del caso. Por otra parte, conviene matizar que ninguna intervención constituye un proceso lineal, sino que suele haber fluc- tuaciones en los avances. Pese a ello, nuestra hipótesis es que la segunda mitad de la intervención mostrará mayor tasa de conductas positivas que negativas.

Con respecto a los resultados, cabe mencionar que en la mayoría de las variables medidas se han obtenido cambios en la dirección esperada en la segunda mitad del tratamiento con respecto a la primera. La única variable que no ha mostrado los resultados hipotetizados es la referida a verbalizaciones negativas relativas a problemas generales. En este sentido, hay que aclarar que esta medida no ha sido objeto de intervención, aunque la hemos querido analizar para valorar si se producía alguna mejoría a través de la resolución del problema motivo de consulta. Otra razón que se puede aludir es que durante el segundo periodo de intervención coincidieron varias circunstancias (una operación de boca, la aparición de dolores musculares y el periodo de Navidades -época negativamente condicionada por C. por ser fechas asociadas a la pérdida de seres queridos-) que pudieron disparar el número de verbalizaciones negativas durante varias sesiones. A pesar de ello, C. fue capaz de poner en marcha y persistir con las estrategias aprendidas (ej.: continuar con las actividades pese a los dolores) y no beber alcohol. Esto consiguió que su cansancio y/o desánimo no sirvieran de señal para beber y/o quedarse en casa sin hacer nada. Una excepción la constituyó la Sesión 13, en la que se produjo una "caída" significativa debido, entre otros motivos, a los dolores musculares intensos de la cliente. No hay que olvidar que la condición física de C. ha constituido una importante variable disposicional, pues también ha supuesto grandes dificultades a la hora de aplicar ciertas estrategias (ej.: respiración abdominal).

Por otro lado, en la fase de eliminación de la dependencia física mediante control estimular C. evitó completamente las situaciones que pudieran incitarle a beber. No obstante, si bien fueron situaciones arriesgadas, C. las afrontó adecuadamente poniendo en marcha las estrategias adquiridas en consulta. En este sentido, si bien este incumplimiento del control estimular se ha considerado una muestra de poca implicación o motivación por la terapia, realmente podría deberse a un elevado interés por superar su problema y normalizar su vida. Hemos tenido, pues, dificultades a la hora de operativizar esta variable. 
También es importante señalar que, pese a que los resultados han mostrado similar grado de iniciativa a emprender otros cambios en ambas mitades de la intervención, parece que en la segunda mitad el grado de intención para emprender dichos cambios ha superado el mero deseo de aquello que le gustaría modificar, pues C. pidió ayuda explícita sobre temas que le gustaría cambiar (ej.: adelgazar, dejar de fumar, etc.), formuló preguntas concretas, pidió pasos a seguir, etc. lo que además indica una mayor conciencia sobre su estado de salud.

En relación a la variable "motivación por la terapia", las conductas relacionadas con una alta motivación siempre han superado en número a las relacionadas con una baja motivación. El hecho de que se produjera una disminución de las conductas que mostraron una alta motivación en las primeras sesiones no es tanto debido a una disminución del grado de motivación de la cliente, sino que atiende más al hecho de que la terapeuta dejara de insistir y de preguntar por estos aspectos a partir de la explicación del análisis funcional en la Sesión 5. Por lo que, al no ser evocadas este tipo de verbalizaciones, el número total de conductas relacionadas con una alta motivación se ha visto reducido.

Por otra parte, el hecho de que hayan aparecido ganas más puntuales en la segunda mitad del tratamiento es lógico si atendemos al hecho de que no se estaba consumiendo, pues en la primera etapa si a C. le entraban ganas de beber lo hacía. Por tanto, aunque siguen apareciendo esas ganas de beber, en situaciones puntuales, no llegan a discriminar la conducta de ingesta.

Cabe señalar que C. ya disponía en su repertorio de ciertas habilidades. No fue necesario entrenarla en asertividad, pues era capaz de rechazar cualquier ofrecimiento de bebida sin problema. Asimismo, pese a que decía tener ya la habilidad de cortar pensamientos negativos, se le entrenó en la parada de pensamiento adquiriendo mayor eficacia con dicha técnica.

\section{Conclusiones}

En primer lugar, queríamos explicar que el hecho de centrarnos más en el problema de consumo, pese a existir una demanda más amplia (problema con su imagen corporal y adicción al tabaco), se ha debido al grado de relevancia que tenía para la propia cliente y a las consecuencias que podía implicar para su salud. No obstante, el abordaje de ese objetivo sí que ha implicado la consecución de objetivos paralelos. También es importante señalar que la elección del plan de tratamiento ha partido siempre del análisis funcional elaborado.

Tal y como defienden Echeburúa y Corral (1988), el éxito de una intervención debe ser medido atendiendo a diferentes variables (estado anímico, cantidad de ingesta, grado de actividad, contactos sociales, etc.). No obstante, si bien hemos tratado de operativizar y disgregar las diferentes variables de cambio, no podemos olvidar que la intervención es siempre global y que unas mejoras apoyan y potencian otras (y a la inversa), lo que hace a su vez necesario intervenir en todas las áreas que forman parte del problema (y no únicamente en un área específica), con el fin de potenciar esos efectos que podríamos denominar de "generalización".

Por otro lado, si bien se han dedicado algunas sesiones a reestructurar ciertas creencias distorsionadas, se esperó que estas cogniciones también desaparecieran como consecuencia de la activación conductual misma y, cuando se han abordado en sesión, fue para considerar no tanto la veracidad de sus contenidos (pues muchas veces eran racionales -ej.: "mi marido ya no está"-), sino su función (viendo si servían para encaminarse o para alejarse de los objetivos planteados, si robaban mucho tiempo a la cliente, si impedían que pudiese realizar otras cosas en lugar de rumiar, etc.). Por otra parte, dadas las características de la problemática tratada (adicción a una sustancia) y los antecedentes del caso particular (negación y engaños iniciales sobre el problema y el cumplimiento de las tareas, dificultades para abandonar la bebida, etc.) se ha llevado a cabo un control muy estricto durante la fase de intervención y de seguimiento. De hecho, Milán y Mitchell (1991) aluden a la importancia de incidir en el control de los procesos de aprendizaje implicados en el mantenimiento de la conducta de abstinencia.

Durante la fase de seguimiento, en la que actual- 
mente nos encontramos, nos estamos encontrando una falta de implicación por parte de C. con las tareas encargadas y algún olvido de la cita acordada. Estos datos, unidos a cierta información que ha proporcionado su hija y que apuntarían a una posible violación de la abstinencia (algo que resulta contradictorio con lo que sigue asegurando C.), nos plantea la posibilidad de que se haya producido un nuevo consumo y nos obliga a estar alerta al respecto. En cualquier caso, conviene destacar que la propia hija reconoció estar muy sensibilizada con el tema y que posiblemente sesgara algo la información, llegando a reconocer que sospechaba porque le resultaba muy raro que $\mathrm{C}$. no hubiese tenido una sola caída y, aunque no quería desconfiar, le parecía imposible. Por tanto, aunque el nuevo consumo aún no ha sido confirmado por C., en la práctica habrá que estar alerta ante esta posibilidad y trabajar con la cliente la idea de que las recaídas forman parte del proceso y, en caso de que se produzcan, no deben ser consideradas como un fracaso sino como una nueva situación que la ayudará a aprender y a prevenir situaciones futuras de riesgo.

En cualquier caso, queremos aprovechar la evolución, hasta la fecha positiva, de este caso para motivar a los clínicos de cara a la intervención sobre estas problemáticas, ya que es posible obtener resultados positivos (aunque no sin esfuerzo). De hecho, nuestro trabajo también persigue el objetivo de mostrar cómo este problema se puede solucionar sin necesidad de adoptar una perspectiva médica del trastorno $y$, mucho menos, sin tener que considerar a la persona una "enferma de por vida". No obstante, queremos aprovechar estos hechos para advertir a los clínicos de la alta probabilidad de recaídas que existe en este tipo de problemáticas, tal y como indican en sus estudios Collins y Marlatt (1983), así como Freixa (1991), haciéndose necesario llevar a cabo seguimientos muy continuados y prolongados en el tiempo. Por tanto, habría que estar alerta para su rápida detección, y contar con que no siempre va a ser reconocida por el cliente, por lo que es siempre conveniente contar con fuentes de información alternativas. En caso de producirse un nuevo consumo, la labor a partir de ese momento sería motivar de nuevo a la persona para reiniciar el proceso de abandono de la bebida, haciéndole ver que estas recaídas son normales y forman parte del proceso de cambio (Marlatt y Witkiewitz, 2005), algo que también hay que trasmitir a la familia para que no considere que se trata de una "causa perdida". Asimismo, habría que analizar la recaída, tanto sus determinantes situacionales como las atribuciones que la persona realiza en relación a la primera caída, tal y como sugieren Marlatt y Gordon (1985) y Echeburúa (1993), para que en vez de ser el inicio del fracaso, sea una situación de la cual aprender para prevenir situaciones de riesgo futuras, pues se ha demostrado que la transgresión de la abstinencia facilita la pérdida de control posterior (Echeburúa, 1986).

Por otra parte, este artículo nos ha permitido confirmar que los problemas que se observan en el ámbito clínico con las personas afectadas por una dependencia o adicción al alcohol van más allá del mero consumo de alcohol. Son muchos los problemas sociales, económicos y de salud que habitualmente presentan estas personas y que dificultan aún más el pronóstico terapéutico de un cuadro clínico que, por sí mismo, es muy resistente al cambio. En este sentido, el buen grado de ajuste premórbido es un factor importante de buen pronóstico, ya que permite centrar la intervención en la recuperación de estrategias conductuales que ya figuraban dentro del repertorio de la persona, sin necesidad de crear nuevas estrategias de afrontamiento (o creando las menores posibles).

\section{Extended Summary}

This paper analyses the case of C., a woman treated for alcohol addiction and other associated problems. The aim is to present a case which has been successfully tackled with behavioral therapy, and where all progress achieved can be explained through the operationalization of change measurements.
In the elaboration of this article, 20 sessions were taken into account. The case is currently in the monitoring phase. First, the most relevant information about the case is presented, as well as the analysis. The origin and maintenance hypotheses are described, together with the variables that 
led to the problem. After that, the two intervention models for alcohol abuse problems (the medical and the psychological models) are presented, as well as their differences and the reasons for the choice of the latter for these problems. In the next section, the different psychological techniques used to achieve the aims (the total withdrawal of alcohol consumption -teetotalism- and the improvement of mood) are listed and explained. It is important to say that controlled alcohol use is possible, but in this case this aim was not chosen for various reasons, which are set out in the article. The goal of the removal of alcohol consumption is the withdrawal of both the physiological and the psychological dependency. The results of the change measurements are also presented and discussed. In the final section, some observations about this type of intervention are made. Alcohol abuse is difficult to change and needs to be tackled together with other problematic areas to ensure success. The collaboration of relatives and acquaintances is also very important.

With regard to the case in question, the high number of problematic areas for the client is remarkable, as well as her initial reticence to let other people collaborate, and to complete the tasks assigned after the sessions. Nevertheless, these difficulties were solved during the intervention. The change measurements were taken from the records of the verbalizations made during the sessions. These were obtained by recording the sessions, which was permitted by both the client and the centre, so that the measurements would be accurate. It is important to mention that the requests considered during the intervention were, in this order of importance, her alcohol abuse and her poor mood. Other problematic areas (such as insomnia, low satisfaction with her image, a high smoking rate) have not been treated, in accordance with the client's wishes.

The change measurements do not only take into consideration the consumption of alcohol, but also analyze changes in verbalizations and behaviors in other problematic areas. We put forward the hypothesis that in the second part of the treatment (the last 10 sessions) adequate or positive behaviors will increase, whereas inadequate or negative behaviors will decrease in comparison to the first part of the treatment (the first 10 sessions). The measurements were made by comparing the relative percentage appearances of verbalizations and behaviors in the first and second part of the intervention. The hypothesis is confirmed since the results show the trend described. It is important to say that not every variable was targeted during the treatment, so it can be said that the improvement in all of them represents a generalization of the learning during the treatment. However, the hypothesis has been confirmed in spite of the fluctuations that appeared during treatment, an effect commonly observed in all treatments. The only measurement against the hypothesis posed is the one regarding the negative verbalizations of the client about problematic areas in her life. This point is explained in the article.

\section{Agradecimientos}

Al Instituto Terapéutico de Madrid (ITEMA) por facilitarnos los recursos necesarios para analizar este caso.

\section{Referencias}

Barraca, J. (2010). Aplicación de la Activación Conductual en un Paciente con Sintomatología Depresiva. Clínica y Salud, 21, 183-197.

Beck, A. (2002). Terapia cognitiva de la depresión. Desclée de Brouwer.

Cáceres, J. (1985). Alcoholismo y "beber controlado": Historia de una polémica. Revista Española de Terapia del Comportamiento, 2, 241-261.

Calvo, R. (1983). Tratamiento conductual del alcoholismo. Estudios de Psicología, 13, 10-27.

Casas, M. (1994). Psicopatología y alcoholismo. Barcelona. Citrán.

Collins, R. L. y Marlatt, G. A. (1983). Failures in the treatment of addictive behaviors. En E. G. Foa y P. M. Emmelkamp (Eds.). Failures in behavior therapy. New York: Wiley.

Echeburúa, E. (1986). Prediction of Relapse in alcoholics: A psychological model. En A. Tongue y E. Tongue (Eds.): 31 International Institute on the Prevention and Treatment of Alcoholism. Rome: Centro Italiano di Solidarietá. 
Echeburúa, E. (1990). Evaluación y tratamiento de un caso clínico de consumo abusivo de alcohol. En M. A. Vallejo, E. G. Fernández-Abascal y F. J. Labrador (Eds.). Análisis de casos clínicos en Modificación de Conducta, Madrid: Edic. Tea.

Echeburúa, E. (1993). Evaluación y Tratamiento de los Trastornos Adictivos. Fundación Universidad de Empresa.

Echeburúa, E. y Corral, P. (1988). El objetivo de beber controlado en el tratamiento del alcoholismo: perspectivas y limitaciones. Psicopatología, 8, 17-28.

Ellis, A. y Grieger, R. (2000). Manual de Terapia Racional Emotiva. Desclée de Brouwer.

Fernández-Montalvo, J. y Lorea, I. (2005). Tratamiento psicológico en un caso de alcoholismo. En J. P. Espada, J. Olivares y F. X. Méndez (Coords.), Terapia Psicológica: Casos prácticos. Madrid: Pirámide.

Fernández-Montalvo, J. y Landa, N. (2003). Comorbilidad del alcoholismo con los trastornos de personalidad. Clínica y Salud, 14, 27-41.

Freixa, F. (1991). Tratamiento psicológico de la adicción al alcohol. En G. Buela-Casal y V. E. Caballo (Eds.). Manual de psicología clínica aplicada. Madrid: Siglo XXI.

Froján, M. X., Alpañés, M., Calero, A. y Varga, I. (2010). Una concepción conductual de la motivación en el proceso terapéutico. Psicothema, 22, 556-561.

Froján, M. X., Montaño, M. y Calero, A. (2006). ¿Por qué la gente cambia en terapia? Un estudio preliminar. Psicothema, 18, 797-803.

Froján, M. X., Montaño, M., Calero, A. y Ruiz, E. (2011). Aproxi-mación al Estudio Funcional de la Interacción Verbal entre Terapeuta y Cliente Durante el Proceso Terapéutico. 1er. Premio de la XVII edición del Premio de Psicología Aplicada Rafael Burgaleta 2010. Clínica y Salud, 22, 6985.

Graña, J. L. y Carrobles, J. A. (1991). Condicionamiento Clásico en la adicción. Psicothema, 3, 87-96.

Hodgson, R. J. (1991). Substance Misuse. Behavioural Psychotherapy, 19, 80-87.

Laberg, J. C. (1990). What is presented, and what prevented, in cue exposure and response preven- tion with alcohol dependent subjects? Addictive Behaviors, 1, 3-4.

Maisto, S. A., O’Farrel, T., Connors, G., McKay, J. y Pelcovits, M. (1988). Alcoholics' attributions of factors affecting their relapse to drinking and reasons for terminating relapse episodes. Addictive Behaviors, 13, 79-82.

Marlatt, G. A. y Gordon, J. R. (Ed.) (1985). Relapse Prevention: Maintenance strategies in the treatment of addictive behaviors. New York: Guilford Press.

Marlatt, G. A. y Witkiewitz, K. (2005). Relapse prevention for alcohol and drugs. En G. A. Marlatt. Relapse prevention: Maintenance Strategies in the Treatment of Addictive Behaviors (pp. 1-44). Guilford Press.

McCrae, J. R., Scales, M. T. y Siegel, S. (1987). The contribution of pavlovian conditioning to drug tolerance and dependence. Alcoholism: British Journal of Addiction, 82, 371-380.

Milán, M. A. y Mitchell, Z. P. (1991). La generalización y el mantenimiento de los efectos del tratamiento. En V. E. Caballo (Ed.), Manual de Técnicas de Modificación de Conducta. Madrid: Siglo XXI.

Nathan, P. E. (1982). Alcoholismo. En H. Leitenbeg. Modificación y Terapia de Conducta. Tomo I. Edad Adulta. (pp. 21-76). Madrid: Morata.

Oblitas, L. (2009). Psicología de la salud y calidad de vida. Cengage Learning Editores.

Peck, D. (1981). Progresos en el estudio y tratamiento del alcoholismo. En D. Peck y J. Cáceres. Avances en la terapia de conducta. Bilbao: Universidad de Deusto.

Petrakis, I. L., González, G., Rosenheck, R. y Krystal, J. H. (2002). Comorbidity of Alcoholism and Psychiatric Disorders. Alcohol and Comorbid Mental Health Disorders, 26, 80-91.

Sanz, J. y Vázquez, C. (1999). Atención selectiva y depresión: una revisión crítica. Ansiedad y estrés, 5, 191-216.

Segura, M., Sánchez, P. y Barbado, P. (1991). Análisis funcional de la conducta: un modelo explicativo. Granada: Servicio de publicaciones de la Universidad de Granada.

Seva, A. y Vázquez, J. J. (1982). Aspectos socioculturales del alcohol y de las drogas de procedencia 
terapéutica. Análisis y Modificación de Conducta, 3, 30-49.

Solomon, K. E. y Annis, H. M. (1989). Development of a scale to measure outcome expectancy in alcoholics. Cognitive Therapy and Research, 13, 409-422.
Valero, L. (31/10/2009). Análisis de Caso. Recuperado el día 17 de octubre de 2011, de http://www.conducta.org/articulos/analisis_caso.htm.

Vallejo, J. y Gastó, C. (2000). Trastornos afectivos: ansiedad y depresión. Elsevier España.

Artículo recibido: 10/06/2011

Revisión recibida: 20/10/2011

Aceptado: 01/12/2011 